$$
L A-S \cup B--96-53
$$

\title{
NEEDS ASSESSMENT
}

for

\section{FIRE DEPARTMENT \\ SERVICES and \\ RESOURCES}

\section{for the \\ LOS ALAMOS NATIONAL LABORATORY, LOS ALAMOS, NEW MEXICO}

Beatty, Harvey \& Associates

12 West 32nd Street

New York, New York

LANL CONTRACT No. B 000720015-35

Final Report: November 15, 1995 


\section{DISCLAIMIER}

Portions of this document may be illegible in electronic image products. Images are produced from the best available original document. 
November 15, 1995

University of California

Los Alamos National Laboratory

Attn: Mr. James R. Jefferies, BUS 5-3, P274

and

Mr. James R. Gourdoux, FSS-21, D427

Ref: B00720015-35

P.O. Box 1663

Los Alamos, NM, 87545

Gentlemen,

It is my pleasure to submit herewith three (3) copies of the Final Report NEEDS ASSESSMENT FOR FIRE DEPARTMENT SERVICES and RESOURCES for the LOS ALAMOS NATIONAL LABORATORY.

It is my belief that the report clearly identifies the needs of the Laboratory in terms of fire department services, describes viable options for the delivery of those services and offers recommendations for the improvement of fire department services and overall level of fire safety.

More importantly, this report calls to the reader's attention a series of conditions and trends which indicate a significantly increased risk of fire at LANL, a situation which we believe to be a severe threat to the institution, its mission and its surroundings.

We urge senior management to move swiftly to implement its recommendations and thereby assure an acceptable level of fire protection at the Laboratory and its environs.

Trusting that you find this information to be of value, I remain,

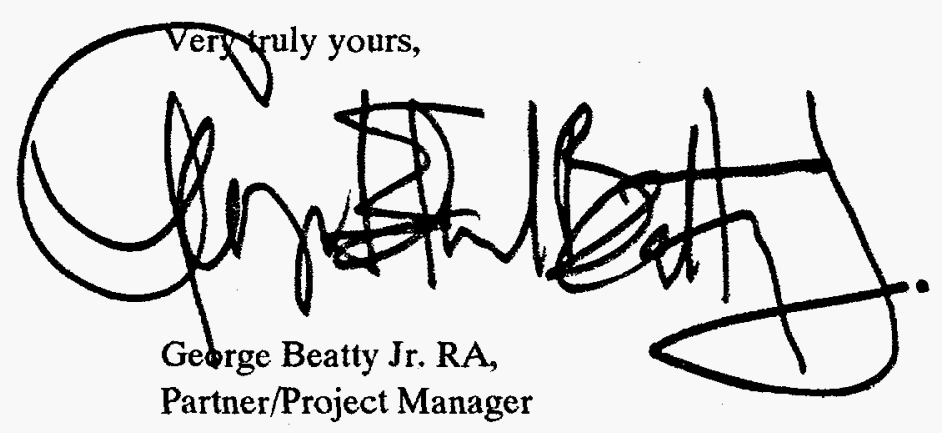




\section{TABLE OF CONTENTS}

TRANSMITTAL LETTER

Executive Summary

1.0 Goals

2.0 Methodology

3.0 Findings

4.0 Needs.

5.0 Conclusions

6.0 Delivery Options

7.0 Recommendations .................... 2

8.01993 Assessment Update $\ldots \ldots \ldots \ldots \ldots \ldots \ldots \ldots 4$

Introduction $\ldots \ldots \ldots \ldots \ldots \ldots \ldots \ldots \ldots \ldots$

1.0 Acknowledgements $\ldots \ldots \ldots \ldots \ldots \ldots \ldots \ldots \ldots$

Goals and Objectives $\ldots \ldots \ldots \ldots \ldots \ldots$

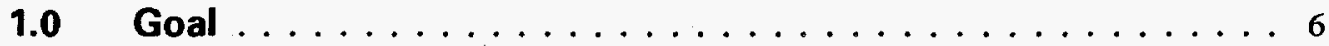

2.0 Objectives $\ldots \ldots \ldots \ldots \ldots \ldots \ldots \ldots \ldots \ldots \ldots \ldots$

Methodology $\ldots \ldots \ldots \ldots \ldots \ldots \ldots \ldots \ldots \ldots$

$1.0 \quad$ LANL $\ldots \ldots \ldots \ldots \ldots \ldots \ldots \ldots \ldots \ldots \ldots$

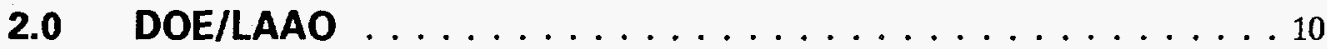

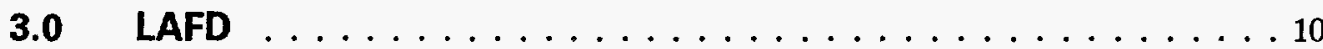

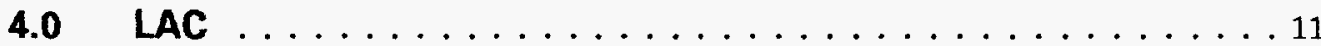

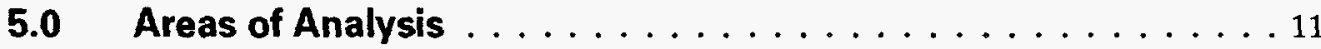

6.0 Deliverables/Schedule . . . . . . . . . . . . . . . 12

$6.1 \quad$ Initial Report . . . . . . . . . . . . . . . . . 12

6.2 Draft Reports (2) . . . . . . . . . . . . . . . 12

6.3 Final Report. . . . . . . . . . . . . . . 13

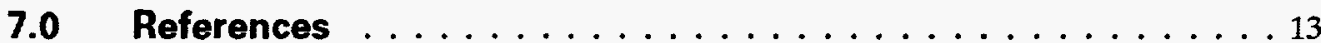

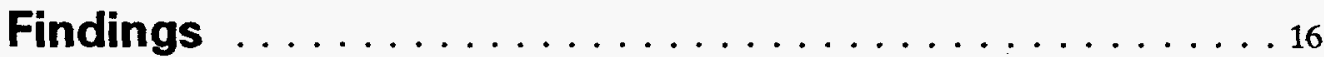

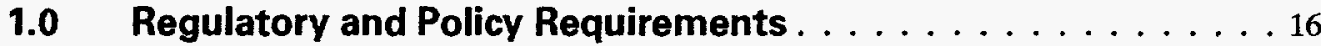

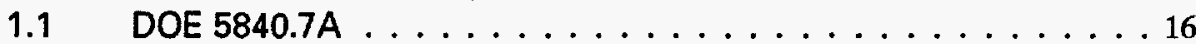

1.2 Director's Policy . . . . . . . . . . . . . . . 16

1.3 Fire Protection Program . . . . . . . . . . . . . . . 17

1.4 The $\$ 50,000,000$ Fire $\ldots \ldots \ldots \ldots \ldots \ldots \ldots . \ldots 18$

1.5 DOE Orders 420 and $470 \ldots \ldots \ldots \ldots \ldots \ldots \ldots$

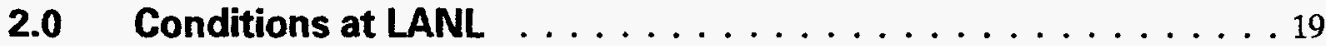

3.0 Conditions within the Community $\ldots \ldots \ldots \ldots \ldots \ldots$

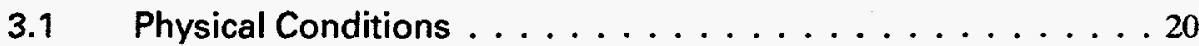

3.2 Mutual Interest . . . . . . . . . . . . . . . 20 
4.0 Conditions in the Los Alamos Fire Department . . . . . . . . . . . 20

4.1 Evaluation/Commitment . . . . . . . . . . . 20

4.2 Improvements . . . . . . . . . . . . . . 21

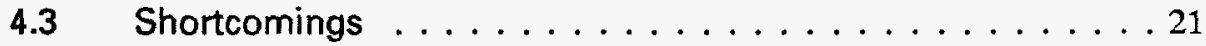

Assessment of Needs . . . . . . . . . . . . . . . . . . . 23

1.0 Risk and Acceptable Losses . . . . . . . . . . . . . . . . . 23

2.0 Self Reliance . . . . . . . . . . . . . . . . . . . . 23

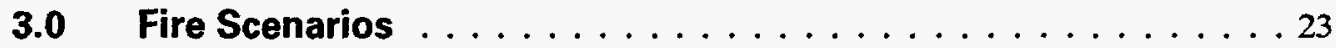

$3.1 \quad$ Building No. 1/TA-43 . . . . . . . . . . . . . 24

3.2 Building No. 132/TA-3 . . . . . . . . . . 25

$4.0 \quad$ Needs . . . . . . . . . . . . . . . . . . . 27

$4.1 \quad$ Need/General . . . . . . . . . . . . . . . . . 27

$4.2 \quad$ Need/Day to Day . . . . . . . . . . . . . . . . . . . 27

4.3 Other Services . . . . . . . . . . . . . . 28

$4.4 \quad$ Leadership and Support . . . . . . . . . . . . . . . . 29

$4.5 \quad$ Need/Major Incidents . . . . . . . . . . . . . . . . . 29

4.6 Community Needs . . . . . . . . . . . . . 30

Conclusions $\ldots \ldots \ldots \ldots \ldots \ldots \ldots \ldots \ldots \ldots \ldots \ldots \ldots \ldots$

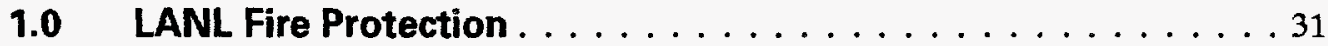

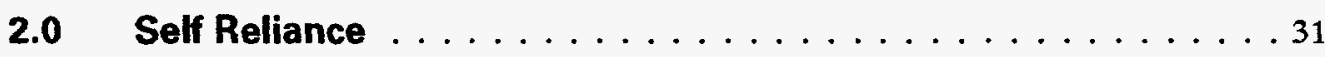

3.0 Fire Department Services . . . . . . . . . . . . . . . 31

4.0 Los Alamos Fire Department . . . . . . . . . . . . . . . . . 32

$5.0 \quad$ Major Loss Risk . . . . . . . . . . . . . . . . . . 32

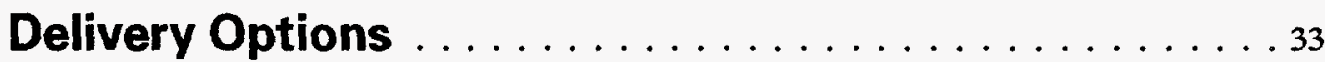

1.0 DOE Fire Department $\ldots \ldots \ldots \ldots \ldots \ldots \ldots \ldots$

2.0 In-House Fire Department . . . . . . . . . . . . . 33

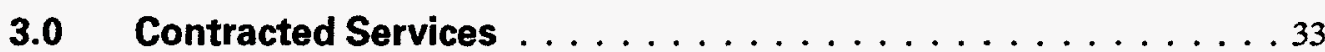

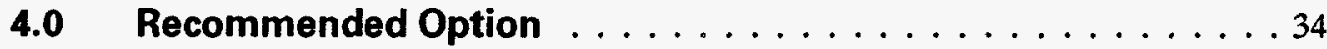

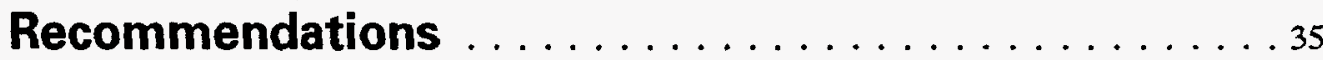

1.0 Organization and Management $\ldots \ldots \ldots \ldots \ldots \ldots$

2.0 Personnel . . . . . . . . . . . . . . . . . . . 36

$2.1 \quad$ Personnel/On Duty $\ldots \ldots \ldots \ldots \ldots \ldots$

2.2 Personnel/On Call ... . . . . . . . . . . . . . 37

2.3 Location of Fire Stations/Response Time . . . . . . . . . 39

$2.4 \quad$ Apparatus . . . . . . . . . . . . . . . . 40

2.5 Alarm Response to LANL Leased Spaces . . . . . . . . . . . 41

2.6 Communications and Dispatch . . . . . . . . . . 41

2.7 Property and Equipment Maintenance . . . . . . . . .41

2.8 Training/Pre-fire Planning . . . . . . . . . . . . 43

2.9 Hazardous Materials Incident Response. . . . . . . . . . . . 44

2.10 Wildland Fires ................... . . . . .

2.11 Mutual Aid ................... . . . . . . 
2.12 Emergency Medical Services . . . . . . . . . . . . . 48

2.13 Fire Prevention . . . . . . . . . . . . . . . . . . 49

2.14 Acceptable Loss . . . . . . . . . . . . . . . . . . . . . . . . . 49

2.15 Development of Operational Procedures . . . . . . . . . . . . 49

2.16 Airport Crash/Fire Rescue Service . . . . . . . . . . . . . 49

1993 Needs Assessment Update . . . . . . . . . . . . . . . 50

Introduction $\ldots \ldots \ldots \ldots \ldots \ldots \ldots \ldots \ldots \ldots \ldots \ldots \ldots$

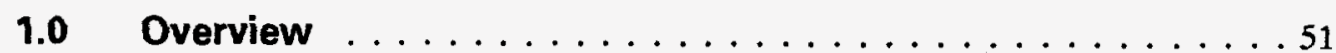

$1.1 \quad$ Background of the Study . . . . . . . . . . . . . . 51

1.2 Goals and Objectives of the Study . . . . . . . . . . . . . 51

1.3 Study Team . . . . . . . . . . . . . . . . 51

1.4 Methodology . . . . . . . . . . . . . . 51

2.0 Fire Department Services Agreement . . . . . . . . . . . . 51

3.0 Fire Service Area Description . . . . . . . . . . . . . . . . . 51

3.1 Los Alamos National Laboratory (LANL) . . . . . . . . . 52

3.2 Los Alamos County (LAC) . . . . . . . . . . . . . 52

4.0 Future Development . . . . . . . . . . . . . . . 53

$4.1 \quad$ Planning Assumptions . . . . . . . . . . . . . . . 53

4.2 Los Alamos National Laboratory . . . . . . . . . . . . . . 53

$4.3 \quad$ Los Alamos County . . . . . . . . . . . . . . . . 53

4.4 Impact on Fire and Emergency Services . . . . . . . . . . 54

4.5 Significant Developments Which Might Influence Needs . . . . 54

Needs Assessment . . . . . . . . . . . . . . . . . . 55

1.0 Existing Conditions Related To Fire Department Services . . . 55

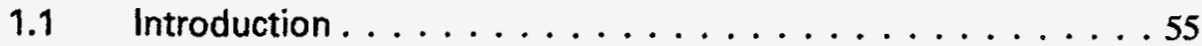

1.2 Los Alamos National Laboratory . . . . . . . . . . . . . . . . . . . . . . . . . . . .

1.3 Hazardous Materials ... . . . . . . . . . . . . . . . . . . . . . . .

1.4 Service Demand History . . . . . . . . . . . . . 56

1.5 Service Demands Projections . . . . . . . . . . . . . 57

1.6 Insurance Services Office (ISO) Rating . . . . . . . . . . 57

1.7 Community \& Wildland interface . . . . . . . . . . . 57

2.0 Existing Conditions - Fire Department $\ldots \ldots \ldots$. . . . . 57

2.1 Organization \& Management . . . . . . . . . . . . 57

2.2 Management Information Systems. . . . . . . . . . . 58

2.3 Staffing Patterns . . . . . . . . . . . . . . . . 58

2.4 Training, Training Program and Facilities. . . . . . . . . . . 59

2.5 Suppression Strategy and Tactics . . . . . . . . . . 60

2.6 Fire Stations and Other Facilities . . . . . . . . . . . 60

$2.7 \quad$ Apparatus \& Equipment . . . . . . . . . . . . 61

2.8 Hazardous Materials Response and Resources . . . . . . . . 62

2.9 Emergency Communications . . . . . . . . . . . 63

2.10 Fire Prevention Program (Community Only) . . . . . . . . 64

2.11 Alarm Response Assignments . . . . . . . . . . . . . 64

2.12 Response Times ....................65

2.13 Wildland Interface .................65 
2.14 Mutual Aid . . . . . . . . . . . . . . . . .65

2.15 Airport Crash/Fire Rescue (CFR) Service DOE has determined both CFR units are not adequate. ..........666

2.16 Ambulance Services . . . . . . . . . . . . 66

2.17 Wildfire Suppression .................67

2.18 Pre-Emergency Planning . . . . . . . . . . . . . 68

3.0 Needs Assessment and Recommendations . . . . . . . . . . 68

$3.1 \quad$ Levels of Fire Services Required . . . . . . . . . . . 68

3.2 Level of Ambulance Services . . . . . . . . . . . . 68

3.3 Applicable Standards . . . . . . . . . . . . . . 69

3.4 Fire Department - General Recommendations . . . . . . . 69

3.5 Fire Department - Suppression Services Recommendations . . 71

3.6 Alarm Response . . . . . . . . . . . . . . . . 71

3.7 Response Times . . . . . . . . . . . . . . . . . 72

3.8 Fire Prevention . . . . . . . . . . . . . . 72

3.9 Hazardous Materials Recommendations . . . . . . . . . 73

3.10 Pre-Fire Planning Recommendations . . . . . . . . . 73

3.11 Wildland Fire Recommendations . . . . . . . . . . . 74

3.12 Ambulance Services Recommendations . . . . . . . . . . 74

3.13 Mutual Aid Recommendation/Fire Services . . . . . . . . . . 75

3.14 DOE/LANL Recommendations . . . . . . . . . . 75

\title{
DISCLAIMER
}

\begin{abstract}
This report was prepared as an account of work sponsored by an agency of the United States Government. Neither the United States Government nor any agency thereof, nor any of their employees, makes any warranty, express or implied, or assumes any legal liability or responsibility for the accuracy, completeness, or usefulness of any information, apparatus, product, or process disclosed, or represents that its use would not infringe privately owned rights. Reference herein to any specific commercial product, process, or service by trade name, trademark, manufacturer, or otherwise does not necessarily constitute or imply its endorsement, recommendation, or favoring by the United States Government or any agency thereof. The views and opinions of authors expressed herein do not necessarily state or reflect those of the United States Government or any agency thereof.
\end{abstract}




\section{Executive Summary}

\subsection{Goals}

- This report has been developed in response to a request from the Los Alamos National Laboratory (LANL) to evaluate the need for fire department services so as to enable the Laboratory to plan effective fire protection and thereby:

- meet LANL's regulatory and contractual obligations

- interface with the Department of Energy (DOE) and other agencies on matters relating to fire and emergency services

- ensure appropriate protection of the community and environment

\section{$2.0 \quad$ Methodology}

- This study is an outgrowth of the 1993 Fire Department Needs Assessment (prepared for DOE) but is developed from the LANL perspective.

- The study has been developed on the basis of interviews and observations rather than in-depth investigation and documentation.

- Input has been received from cognizant and responsible representatives at LANL, DOE, Los Alamos County (LAC) and the Los Alamos Fire Department (LAFD).

\subsection{Findings}

- Regulatory and policy requirements at LANL require accessibility to and service by a well established fire department.

- The LANL Fire Protection Program presupposes the availability of a fire department equal to the task of both day-to-day and major fire incidents.

- Existing conditions relating to fire safety at LANL have deteriorated in the three year period since the study team's initial inspection. Programs with significant perils have been initiated or expanded. Budget constraints have limited or delayed activities which would promote fire safety at LANL. These trends continue.

- LAFD has markedly improved its operations, particularly with respect to organizational and management, training, utilization of resources, pre-fire planning and physical conditioning.

Notwithstanding LAFD's improvements, there remain serious shortcomings in the Department's abilities to address major or complex or simultaneous fires. Training and pre-fire planning, while improved, does not adequately address site-specific LANL conditions.

\subsection{Needs}

- LANL needs - "to have access to a fully staffed, trained and equipped fire department/brigade." 
- Redundant fire protection systems, of which fire department services are a critical component, are needed at LANL.

- As part of its need for redundant fire protection systems, LANL must have fire department (and emergency medical services) which adequately provide for both initial response of two alarms and major fire incidents.

- Special fire department services needed at LANL include standby protection at the Los Alamos Airport, wildland fire protection, and Haz-Mat response services.

5.0 Conclusions

- Geographic conditions make self reliance an essential element at LANL.

- LANL must have fire department services for day-to-day requirements equal to a two alarm response, a minimum of twenty-nine (29) firefighters per on-duty shift.

LANL must have available fire department resources of at least one-hundred-fifty (150) personnel to defend against major fire incidents.

- LAFD has improved in some areas but still has significant shortcomings. LAFD does not have the capabilities to deal with a major fire at LANL.

- Fire protection at LANL has deteriorated in the three years since the initial DOE Needs Assessment. This condition has serious adverse impact on fire safety at the Laboratory.

- LANL is at serious risk of loss from any fire which exceeds two alarms in size. Catastrophic incidents are well beyond the capabilities of LAFD as now constituted.

\subsection{Delivery Options}

- DOE Fire Department services should be based on the needs analysis and recommendations herein.

- An in-house fire brigade is not a recommended option for LANL.

- Contracted fire department services could be provided by private vendors or LAC/LAFD. LAC would be a highly motivated bidder for a direct fire department services contract.

- Contracted services through a single professional provider is the delivery mode recommended by the consultants.

\subsection{Recommendations}

- Fire department and emergency medical service should be an integral part of overall emergency management planning at LANL. 
- Fire should be recognized by LANL as a significant threat to the institution, its surroundings and its mission. Responses to this threat should have high priority.

- Fire department services to LANL and the community should be provided by a single, professional entity.

- On-duty personnel requirements should be adequate for a first and second alarm at LANL. A total of twenty-nine (29) firefighters is needed in accordance with NFPA standards for high risk structures.

- To meet LANL's day-to-day needs, a three shift compliment of one-hundred-one (101) personnel is required.

- To meet LANL's needs for major fire incidents a fully trained and equipped ON-CALL RESER VE of one-hundred-fifty (150) firefighters and technical specialists should be developed by LAFD.

- LAFD call-back procedures should be improved.

- Three fire stations are required to meet the specific needs at LANL $(1,3$ and 5) This condition should be monitored for future changes.

- Station 6 may be needed until the cleanup of TA-21 is complete.

- Response times should be reevaluated.

- Fire apparatus should meet NFPA guidelines.

- Alarm response to LANL leased facilities should be consistent with those of the community.

- Communication and dispatch should be centralized at LAC.

- Communications systems should be networked with other agencies.

- LAFD maintenance procedures should meet NFPA recommendations.

- LANL maintenance procedures should stress reliability of fire protection systems and be adequate to that task.

- Pre-fire planning and training should be site-specific.

- LAFD should conduct realistic drills to test pre-fire plans.

- LAFD pre-fïre plans should contain additional site-specific information.

- LANL should continue to serve as a technical resource for the Haz-Mat incident response.

- LAFD should provide Haz-Mat services at LANL. 
- LAFD should provide "bomb-squad" services at LANL and within the community.

- LAFD should have adequate equipment and manpower to provide initial wildland fire defense.

- LANL should expedite the removal of decommissioned structures.

- LANL should undertake appropriate prescribed burns and other control procedures.

- Mutual Aid agreements should be recognized as having limited value for LANL. Nevertheless, such relationships should be expanded.

- LAFD should provide EMS service.

- EMS mass-casualty transportation capabilities should be expanded.

- LANL should provide physical fitness and wellness services to LAFD.

- LAFD should expand its "building inspection" activities at LANL so as to improve on-site familiarity.

a LANL should improve its methods for advising LAFD of changes in fire risk conditions.

- Airport Crash-Fire Rescue capabilities should be maintained.

\subsection{Assessment Update}

- Comments are provided which highlight changed conditions affecting the need for fire department services at LANL. 


\section{Introduction}

On August 9, 1995, in response to a request from the Los Alamos National Laboratory (LANL), Beatty, Harvey and Associates (BHA) submitted a proposal to undertake a study entitled NEEDS ASSESSMENT FOR (LANL) FIRE DEPARTMENT SERVICES AND RESOURCES.

This effort reflects the recognition by LANL that many conditions, resources and expectations identified in the 1992 study for the Department of Energy (DOE) entitled: NEEDSANALYSIS and MASTERPLAN (also prepared by Beatty, Harvey and Associates and it's subdivision, International Fire Consultants, Inc.) had significantly changed, thus affecting the level of fire department services provided to and required by LANL.

While the precise timing was surprising, the likelihood of such a request was clearly envisioned by the consultant team which noted in its original evaluation that... "The reader is cautioned that long-range plans must always allow for adaptation to changing conditions."

The original evaluation went on to identify many of the specific events which have prompted this re-analysis. These included changes in the LANL mission, in the types and location of significant structures, in the number and classification of personnel, regulatory requirements and, most significantly, changes in the resources available to assure fire safety.

Equally important, the original analysis was developed under a contract with the Department of Energy and focused its attention on the implementation of the existing contract for fire department services between DOE and the Los Alamos County Fire Department.

Given the rapidly changing conditions and the specific focus of the original study, prudent managers at LANL are well advised to seek information which reflects current and projected conditions and does so from the specific perspective of LANL.

This Needs Assessment will address these issues and offer recommendations and guidance to assist LANL management in the continued development of an effective Fire Protection Program.

\subsection{Acknowledgements}

This report would be severely lacking without words of acknowledgement and thanks to the LANL staff and management, particularly those of FSS-21 and FSS-20.

The consultant team was granted full latitude to inquire and observe conditions which we believed to be important to our investigations. As a result, we are confident that this report is as accurate and complete an evaluation as time and security constraints allow. The conclusions and recommendations arising from these investigations represent our best judgement on a matter of utmost concern, that of safety and the threat of fire at LANL. 


\section{Goals and Objectives}

\section{$1.0 \quad$ Goal}

The stated goal of this effort is the identification of the level of fire department services required by LANL so as to allow LANL to successfully and effectively:

- plan and manage the critical emergency and fire protection programs for the Laboratory

- address compliance issues regarding the protection of LANL personnel, facilities and the environment

- interface with the Department of Energy, Los Alamos County and the Los Alamos Fire Department for LANL emergency management and fire protection responsibilities

- ensure that the Community and other off-site locations are properly protected from the effects of fire on LANL property

\section{$2.0 \quad$ Objectives}

To achieve the primary goal one must have a clear understanding of the LANL mission and be fully aware of the conditions which determine the needs for fire department services and shape the delivery mode for those services.

To develop this level of awareness the consultant team has sought to accomplish the following:

- define the mission and policy of LANL with respect to fire protection and safety.

- define the priorities of LANL with respect to fire protection and safety.

- define regulatory and contractual obligations of LANL with respect to fire protection and safety.

- define the level of fire risk deemed acceptable to LANL and DOE.

- define the level of fire safety to be found in LANL facilities. Identify trends where applicable.

- define the in-house resources at LANL which contribute to fire defense.

- define the most demanding fire risks and identify those which will set benchmarks for fire department service levels. 
After definition of the conditions which establish the need for fire department services, the consultant team has sought to accomplish the following:

- define and quantify the fire suppression services required for day-to-day operations at LANL.

- identify those services, other than fire suppression, which are essential to the LANL program.

- identify those fire department services required for major incident response.

- define options for the delivery of fire department services.

- provide recommendations for the delivery and improvement of fire department services and such other activities at LANL which will improve the overall level of fire protection. 


\section{Methodology}

This study is an outgrowth and continuation of the original Fire Department Needs Analysis and Master Plan developed by BHA in the period September 1992 to November 1993. The study builds on information developed in the original fourteen-month contract and draws on the expertise of the team which developed the initial analysis and report for DOE. George Beatty and John O'Rourke served in the primary roles on the consultant team.

$1.0 \quad$ LANL

Reflective of LANL's directive that this study continue in a format similar to that of the original report, and further reflective of the short time frame for this effort, the study has drawn heavily on the collective wisdom and insight of LANL managers and specialists to identify key areas of concern, especially those which mark significant changes in conditions at LANL.

The consultant team has identified areas of interest and concern and has worked with LANL personnel to arrange interviews and/or teleconferences with key LANL representatives. These have included persons knowledgeable in the areas of:

- cost containment goals

- master planning (facilities/programs)

- capital construction planning, Critical Assets Management Plan (CAMP)

- decommissioning and disposal activities

- systems maintenance/infrastructure

- fire protection engineering (existing and new facilities)

- emergency management

- risk evaluation

- security and access control

- regulatory and contractual requirements

- interaction with LAFD

- communication

- haz-mat operations

- emergency medical services 
In addition to interviews, the consultant team has reviewed pertinent information and conducted inspections and/or observations to bolster its knowledge and understanding of the specific areas of interest noted above. These activities have included:

- general drive-by tours

- inspections of specific high-fire-risk sites

aerial over-flight of LANL and its environs

- round-table discussions with interested parties

- review of LANL documents, memoranda, federal regulations and standards

Members of the LANL management or technical staff who have contributed to this study include:

- Roger Perkins Deputy Division Leader (Facilities

FSS-DO

Safeguards and Security)

- James Gourdoux

Group Leader/Fire Protection,

FSS-21

LANL Asst. Technical Representative,

Fire Department Contract

- Alice Turner

LANL Asst. Technical Representative

FSS-21

Fire Department Contract

- Betty Northrup Group Secretary

FSS-21

- Stacy Miller

Computer Technician II

FSS-21

- Walter Maybee

FP Engineer

FSS-21

- Robert Farris

FP Inspection Program Lead

FSS-21

- Debra Fontenot

FP Engineer

FSS-21

- Raymond Tell

FP Engineer

FSS-21

- Sidney Pinkston

FP Maintenance Lead

FSS-21

- Walter Martinez

Fire Alarm Maintenance Specialist

FSS-21

- Norman Mayne

- Mike Nicolini

Fire Alarm Maintenance Specialist

FSS-21

- Robin Justice

FP Inspector

FSS-21

- Richard Pearson

FP Inspector

FSS-21

FP Inspector

FSS-21

- Jim Tsiagkouris

FP Engineer

FSS-21

- Allen Trujillo

FP Technician

FSS-21/FSS-6

- George Van Tiem

Group Leader/Emergency Management

FSS-20

and Response

- Gene Darling

Team Leader/Emergency Management

FSS-20

and Response

- Gerald Ramsey

Emergency Responder

FSS-20

- David McIntosh

Program Administrator/Condition

FSS-6

Assessment Survey (\& Pilot for the

LANL flyover)

- Scott Bryan

Emergency Coordinator/Emergency

TA-55

Response Team Chief

- Laura Walker

Haz-Mat Team

ESH-10 
- Dr. Hugh Smith

- Dr. Jerry Williams

- William Purtymun

- William Pelzer

- Kirt Anderson

- Mary Trainor

- Robert Prommel

- John Tucker
Occupational and Health Clinic

Director/Occupational and Health Clinic

TA-54 Waste Disposal Site

Program Manager/Critical Assets

Management Program (CAMP)

LANL Site Development

LANL Strategic Planning

Community Involvement and Outreach (element of LANL Master Planning)

Deputy Program Manager Facilities, Security \& Safeguards
ESH-2

ESH-2

CST-14

FSS-3

FSS-3

QP

CIO

FSS-PAO

\subsection{DOE/LAAO}

To further expand its understanding of the conditions related to fire department services the consultant team has conferred with DOE/National, DOE/LAAO and DOE/Albuquerque representatives to discuss the DOE's expectations and directives.

The participation of Ray Wolf, Technical Advisor, Fire Department Contract; Dennis Kirson, DOE/Albuquerque Fire Protection Engineer; Dennis Kubicki, U.S. DOE/Headquarters Fire Protection Engineer; and Angonne National Laboratory Fire Chief Gordon Veerman have been of significant value to this study.

\subsection{LAFD}

No realistic analysis and plan is possible without a clear understanding of the resources available to provide fire department services.

The Los Alamos Fire Department, as the contractual provider of services to LANL, is crucial to the analysis and planning effort. The consultant team has re-visited its original evaluation of LAFD and undertaken the following activities:

- conferred with LAFD management so as to determine the Department's current resources and capabilities.

- observed the equipment and facilities of LAFD to determine the suitability to the LANL needs.

- reviewed training and pre-fire planning to determine its suitability to LANL needs.

- reviewed other commitments which draw on the resources of LAFD

- reviewed the status of mutual aid agreements

- reviewed the working relationships between LAFD, LANL and DOE 
The participation of the following have been of great value:

- Douglas MacDonald Chief of the Department

- Douglas Tucker Assistant Chief/Operations

- Carlos Orozco Assistant Chief/Fire Marshall

- Hank Blackwell Assistant Chief/Training

- Steve Coburn Battalion Chief/Pre-Fire Plan Coordinator

- Larry Norris Battalion Chief/Safety Officer

- Jerry Keene Communications and Dispatch Director

\subsection{LAC}

Los Alamos County is inextricably tied to the ebb and flow of LANL. Nevertheless, the County has its own obligations, goals and plans independent of LANL, all of which shape the environment wherein fire and emergency services are delivered.

To better acquaint the consultant team with the current conditions and directions of the County a conference has been held with County Administrator Alex Georgieff at which time the LAC viewpoint was discussed in depth.

\subsection{Areas of Analysis}

Having identified the conditions and objectives for fire department services the consultant team has sought to quantify those services and resources required to meet LANL's needs. This effort has also sought to define the most appropriate mode for the delivery of those services at LANL. The specific areas analyzed include:

- organization and management

- personnel (number and classification)

- location of fire stations

- apparatus and equipment

- response times

- composition of response teams

- alarm response criteria

- communications requirements

- dispatch procedures and requirements

- standards for maintenance of equipment

- standards for training (general and specialized) 
- standards for familiarization of the LANL facilities, pre-fire planning

- hazardous materials incident response, resources, training and control

- wildland fire prevention and control

- mutual aid practices and procedures

- emergency medical service procedures, equipment, training and standards for performance

- loss prevention practices and procedures, equipment, training and standards for performance

- airport crash-fire rescue practices and procedure

6.0 Deliverables/Schedule

Based on the discussions at our initial meeting and reflective of the contractual requirements for the study the consultant team has made four submissions.

\subsection{Initial Report}

This document clarified the goals and objectives of the study, presented the methodology and delivery schedule for all submissions and included initial observations and general recommendations. On-site conferences were held on August 8 and August 30-September 1st 1995.

\section{Draft Reports (2)}

These submissions included the following components:

- an assessment of the current and projected conditions to be found at LANL, LAFD and in the community

- identification of LANL's specific needs for fire department services

- conclusions as to the state of fire department services and certain fire safety conditions

- a definition of the benchmark fire scenarios to be used to establish the minimum level of fire services required

- recommendations for the fire department configuration (staffing, training, equipment, response time, etc.), necessary to provide the level of service required by LANL

- recommendations, based on the professional judgement of the consultant team, of the most appropriate delivery mode for fire department services 
- an annotated version of the original Needs Assessment and Master Plan identifying changed conditions affecting fire department services

The delivery dates of the Draft Reports were September 30th, and October 26th, 1995. To facilitate these submissions additional on-site activities have been conducted during the periods of September 8-9th, and September 21-22nd. An additional review meeting was held at LANL on October 26, 1995. Teleconferences have been conducted throughout the months of September and October.

After review and comment by LANL, this Final Report has been prepared. The Final Report addresses all comments and outstanding issues identified in earlier communications.

The amended date for the delivery of the Final Report is November 15th, 1995. An on-site conference is planned on or about November 30th to discuss the Final Report.

\subsection{References}

During the course of this exercise the consultants were provided with or had access to information and reference source material which included:

- Fire Department Needs Assessment and Master Plan as prepared by Beatty, Harvey/International Fire Consultants, Inc. for DOE

- Fire Department Services Contract DOE/LAC

- DOE Order 5480.7A Fire Protection

- DOE Order 6430.1 General Design Criteria Manual (part)

- DOE Orders 420/470 Fire Safety Program Implementation Guide (draft August 23rd, 1995)

- DOE Baseline Evaluation Prototype

- DOE Comparative Study of Fire Departments

- DOE Order 5480.4 Environmental Protection, Safety, and Health Protection Standards.

- DOE Order 5000.3A Occurrence Reporting and Processing of Operations Information.

- DOE Order 5480.9 Construction Safety and Health Program.

- DOE Order 5480.19 Conduct of Operations for DOE Facilities.

- DOE Order 5482.1B Environmental, Safety, and Health Appraisal Program.

- DOE Order 5483.1A Occupational Safety and Health Program for DOE Contractor Employees at Government-owned Contractor-operated Facilities.

- DOE Order 4300.1B Real Property and Site Development Planning.

- DOE Order 4700 Project Management.

- DOE Order 6430.1A Design Criteria.

- AL 5480.4 Environmental Protection, Safety and Health Protection Standards.

- 14 CFR 139 Certification and Operations: Land Airports Serving Certain Carriers. 
- 29 CFR 1910.120 Hazardous Waste Operations and Emergency Response

- State of New Mexico EMS Directory, Laws, Regulations, and Services.

- State of New Mexico, Emergency Medical Services Act.

- State of New Mexico, Health and Environmental Department, Public Health Division, Regulations Governing the Licensing of Emergency Medical Technicians.

- New Mexico Corporation Commission Ambulance Regulations General Order 35.

- New Mexico Hazardous Materials Emergency Response, Plan and Procedures Manual.

- New Mexico Hazardous Materials Emergency Response Program.

- NFPA 1500 Fire Department Occupational Safety and Health Program 1992.

- NFPA 295. Standards for Wildfire Control.

- NFPA 298. Foam Chemicals for Wildland Control.

- NFPA 11A. Standards for Foam Systems, medium and high expansion foam.

- NFPA 11C. Standards for Foam Apparatus, Mobile.

- NFPA Fire Protection Handbook, 17th edition, 1991, National Fire' Protection Association, Quincy, MA.

- LANL Directors Policy 109 Emergency Management.

- LANL Directors Police 118 Fire Protection.

- LANL Capital Asset Management Process Report (FY ‘97).

- Science Based Stockpile Stewardship.

- LANL Emergency Management Plan (Jan. ‘95).

- LANL Institutional Plan (FY 95-2000).

- LANL Site Development Plan, 1990.

- LANL Strategic Planning Memo. August 30, 1995.

- LANL (University of California)/DOE Contract extract on Facilities Management.

- LANL Long Range Water Supply Plan.

- LANL Tactical Goals Report.

- LANL Memo Firefighting and Nuclear Criticality Safety Policy.

- LANL Administrative Requirement II Fire Protection, Fire Extinguishers, Exits and Doors.

- LANL Key Building and Facilities List.

- LANL Building Emergency Planning Status Report (August 8, 1995).

- LANL Facility Manager Assignments and Area Coordinates.

- LANL Facility Management Implementation Guide. 
- Los Alamos Emergency Communication Center Report.

- LAFD 1994 Annual Report.

- LAC Analysis of Economic Impact/DOE.

- LAC Airport Future Report.

- LAFD Review of Needs Assessment Changes.

- LAFD Pre-fire Plans, LANL High Priority Facilities.

- LAFD Goals and Objectives.

- LAFD/LAC Continuity of Operations Plan.

- LAFD/LAC/DOE Memo/Presentation Fire Department Cost Issues.

- LAFD Fire Attack Plan, TA-3/SM132.

- LANL Comparative Manpower Availability Chart. 


\section{Findings}

\section{$1.0 \quad$ Regulatory and Policy Requirements}

1.1 DOE 5840.7A

LANL operates under the provisions of DOE Order 5480.7A "Fire Protection" which applies to all DOE-owned and contractor-operated facilities. The objectives of this order are to:

- minimize the potential for the occurrence of a fire

- ensure that a fire does not cause an on-site or off-site release of radioactive or other hazardous materials that will threaten the public health and safety or the environment

- establish requirements that will provide an acceptable degree of life safety to DOE and contractor personnel and assure that there are no undue hazards to the public from fire and its effects at DOE facilities

- ensure that process controls and safety systems are not damaged by fire or related perils

- ensure that vital DOE programs will not suffer unacceptable delays as a result of fire and its effects

- ensure that property damage from fire and related perils does not exceed a acceptable level

The DOE/LAAO local representative has confirmed that the priorities for fire protection are (in order of importance):

- the protection of human life and the safety of the public

- the protection of the environment

- the continuity of critical programs

- the protection of DOE property and facilities

The DOE/LAAO representative has confirmed that NFPA standards for fire department services apply to the DOE/LAC contract for the LAFD.

\section{Director's Policy}

In response to Order 5480.7A, the Director of LANL has issued Policy Statement No.-118 entitled FIRE PROTECTION which mandates the development and maintenance of a fire protection program which meets DOE objectives by:

- assuring minimal potential for fire occurrence 
- limiting on-site or off-site release of hazardous material from a fire that may threaten public health and safety or the environment

- assuring an acceptable degree of fire and life safety for all personnel, and

- limiting programmatic loss and property damage

The policy statement further mandates that the Laboratory shall comply with DOE orders and all applicable federal, state, and local laws, codes, and regulations, memoranda of understanding, and other agreements relating to fire protection.

The policy statement goes on to affirm that the following fire protection actions shall be part of any Laboratory operation:

- hazards will be identified and evaluated

- hazard control measures will be implemented

- operating personnel will be trained in hazard awareness and control measures

- quality processes will be established to ensure excellence in fire protection and

- conflicts between programmatic initiatives, security requirements, and fire protection compliance and performance will be resolved so that goals for fire protection and life safety are met

\subsection{Fire Protection Program}

To meet the objectives defined in DOE Order 5480.7A and in accordance with the policy defined by Director's Policy 118, a comprehensive Fire Protection Program has been implemented at LANL. The Fire Protection Program encompasses preventative measures, operational controls and protection systems, all intended to prevent or minimize the impact of fire. The fire protection systems include those elements designed to detect, limit and extinguish fire and its related elements. These include automatic detection and suppression systems, process controls, physical barriers, separations and manual systems (a fire department) for the suppression of fire.

DOE Order 5480.7A contains several key provisions with regard to the need for fire department services required as part of the Fire Protection Program. Of these, the most straight forward is the stipulation that -

"A fully staffed, trained, and equipped fire department/brigade shall service all DOE facilities....

While this dictum does not address the qualitative aspects of fire department services, it clearly places a burden on those who manage DOE facilities to assure that such services are available.

DOE provides fire department services to LANL under the terms of its agreement with Los Alamos County and LAFD. 
Fire protection systems, of which fire department services are a component, are most often considered in terms of potential monetary loss resulting from a fire.

DOE Order 5480.7A establishes monetary thresholds wherein specific levels of fire protection must be provided. Any condition where the maximum possible fire loss exceeds $\$ 50$ million (MPFL - the replacement dollar value of plant, equipment and clean-up at risk within a single fire zone, assuming in-place systems fail and manual firefighting is not available) must be provided with redundant fire protection systems.

Redundancy may be achieved with various combinations of active and passive systems including sprinklers, fire separations and manual firefighting services as represented by the fire department. A review of the fire protection concepts envisioned for those facilities at LANL which require redundant protection clearly indicates that fire department services are the option of choice.

Both DOE Order 5480.7A and the GENERAL DESIGN CRITERIA MANUAL of DOE 6430.1 contain provisions which call for a "higher standard of protection" when fire constitutes a threat to public safety, national security, the environment or programmatic continuity.

Clearly, the risks inherent in the concentration of nuclear materials, explosives and other hazardous materials, and the vital programmatic importance of LANL activities meet the DOE standards for an "increased level of protection," a critical element of which is appropriate fire department services.

\section{The $\$ 50,000,000$ Fire}

During the course of this study there was extensive discussion about the role of a fire department in the event of a potential \$50 million MPFL fire. While the DOE documents may be interpreted as suggesting that a fire department must be of such a size and capability as to prevent such a loss, it is the belief of this consultant that such an interpretation is erroneous and impractical. By way of example, an explosive fire could cause $\$ 50$ million in damage to computer systems instantaneously - to say nothing of the cost of environmental cleanup. Clearly, no fire department can defend against such occurrences.

DOE fire protection professionals share our believe in this regard.

\section{DOE Orders 420 and 470}

During the course of this study it became evident that efforts are well advanced to replace DOE 5480.7A with new orders, DOE 420 and 470, which will provide modified directives and guidelines for fire protection and safety. While there is some disagreement as to the effective date for these new regulations, it is clear that $5480.7 \mathrm{~A}$ will be superceded, perhaps as early as November of this year.

That being the case, LANL is cautioned to review the recommendations herewith with an eye toward the new documents whose requirements may well cause further changes in focus and/or implementation. 


\subsection{Conditions at LANL}

The need for fire department services must be evaluated with a clear understanding of the environment in which those services will be delivered.

In accordance with DOE directives and as further recognized in the Directors Policy No. 118, LANL is defined and must be operated as a "highly protected risk," a term used in the fire protection and insurance industries to indicate an improved level of fire defense. The "improved level" of fire protection is most adequately defined by the "Loss Prevention Data Sheets" issued by Factory Mutual. This standard was confirmed by DOE and LANL at the time of the initial FIRE DEPARTMENT NEEDS ASSESSMENT and was reflected in the evaluations and recommendations which followed.

While we found specific instances which tended to call this condition into question, the overall picture at the time was that of a strong commitment to fire safety. Most assuredly, the results spoke for themselves; fires had been few and far between, losses had been limited to levels far below industry expectations.

While change was "in the air" and key indicators of those changes were identified in the original Needs Assessment it was startling to return to LANL three years later and find conditions so dramatically different from those which prevailed in 1992.

Reflective of new geopolicital realities and as a result of cost containment measures adopted by LANL and/or imposed by DOE, we have found, or been made aware of:

- new program initiatives wherein high hazard conditions do not appear to be matched with commensurate protective measures

- scaled back maintenance of fire protection systems resulting in more frequent failures or lessened reliability

- reduced emphasis on fire protection in new and/or proposed facilities

- removal of decommissioned structures is tied to the limited availability of funds

- continuing reliance on more fire-prone temporary and transportable structures

- reduction in fire protection personnel, security patrol and maintenance staff

- reduced accessibility to facilities due to heavier reliance on passive security systems

- reduced level of sensitivity to fire safety on the part of on-site personnel

- fragmentation of approach to fire safety issues

- continued aging of facilities and systems

These conditions were observed and/or reported at a time when increased concerns for safety and security at government facilities nationwide are regularly the topic of front page news articles. 


\subsection{Conditions within the Community}

Observations conducted during the course of this study showed continued building in the community and little reduction in some of the areas of concern identified in the original Assessment wherein firefighting demands could overtax the available resources of LAFD:

- older, pre-code structures remain a significant portion of the housing and commercial building stock in the community

- the proximity of structures and wildlands presents a compound risk

- new occupancies, such as the senior citizen residences now under construction, present new challenges

- the continuing development of structures in close proximity, one to another, presents a risk of "group fires"

- water service lines show evidence of deterioration and the well capacity is being strained

\section{Mutual Interest}

In the course of our interview, County Administrator Alex Georgieff reemphasized the interrelationship of LANL and the community. He is fully aware of the mutuality of interests and the common problems facing both LANL and the community with respect to fire and emergency services.

He forcefully stated the interest of LAC in continuing to provide fire department and emergency medical services to LANL, albeit in a more effective and direct contractual mode.

Mr. Georgieff made clear his belief that LAFD was well qualified to meet LANL's needs as currently defined and is prepared to expand those services if and as required in the future.

Were LANL to move in the direction of direct contracting for fire and emergency services, Los Alamos County would be a highly motivated bidder.

\subsection{Conditions in the Los Alamos Fire Department}

4.1

\section{Evaluation/Commitment}

DOE Order 6430.1 "General Design Criteria Manual" stipulates that the capabilities of a (local) fire department be evaluated in terms of the proximity of its facilities, its staffing and equipment, its methods of fire suppression and its commitment to the defense of DOE facilities. 
Commitment on the personal level can be measured in the light of the dedication and professionalism of individual fire fighters and officers. We have no reason to doubt this commitment on behalf of the men and women of LAFD. We note, however, that reports persist where individual firefighters are said to have an unwarranted fear of firefighting risks at LANL.

In considering commitment on the institutional level, we take note of the dual responsibilities assigned to LAFD by DOE. The LAFD must provide protection to both the community and LANL, a situation which recent events have shown to have severely taxed the capabilities of the LAFD (a large house-fire in White Rock drew nearly the entire on-duty staff of LAFD leaving LANL and the rest of the community virtually unprotected for a period of time).

Were fires to occur simultaneously at LANL and within the community, or were incidents to occur involving the major complicating factors noted above, LAFD would be unable to effectively meet the dual responsibilities as required by the DOE/LAC agreement.

\section{Improvements}

In the two years since this consultant team submitted its MASTERPLAN and RECOMMENDATIONS the Los Alamos Fire Department has made marked improvements in its operations and capabilities.

- organization and management are more professional

- interaction with LANL is much improved

- training has been broadened

- a limited wildland fire capability has been established

- equipment is better utilized

- new equipment has been brought on line

- pre-fire planning (for LANL facilities) has advanced

- physical conditioning of firefighters has been stressed

\subsection{Shortcomings}

There remain, however, significant weaknesses and shortcomings which, from the perspective of LANL, raise serious concerns:

- the depth of available manpower is not sufficient for large scale fire incidents or those with significant technical complications

- mutual aid agreements show little effective value for major incident response 
- pre-fire planning lacks in-depth understanding of many site-specific hazards and programmatic priorities at LANL

- LAFD does not conduct realistic drills to test and sharpen pre-fire planning concepts

- wildland fire equipment is not adequate for an effective response

- LAFD/EMS lacks the capacity to deal effectively with the transportation requirements of a "mass casualty" incident

- experienced staff members may retire as a result of pending pension legislation

- equipment is aging

- communications and dispatch remains uncoordinated

- contractual relationships with DOE remain clouded by the issues of "self sufficiency," cost reduction and administrative confusion 


\section{Assessment of Needs}

1.0 Risk and Acceptable Losses

Fire protection planning begins with an evaluation of risk and a determination of acceptable losses.

Historically, LANL has had a very low probability of fire combined with a very high potential for loss, were a fire to occur. The potential for loss is measured both in readily quantifiable (dollars) and in totally subjective (human life, environmental quality, national defense, programmatic continuity) terms.

While DOE and its contract operators may apply common business principles of cost-benefit analysis to losses measured in dollars, those aspects of fire protection planning dealing with life safety, environmental protection, and national security, are far less quantifiable — and, indeed may be immeasurable.

For these aspects of fire protection the accumulated risks and critical importance of LANL demand the maximum practical commitment.

\subsection{Self Reliance}

The decision to locate LANL on a mountain plateau 35 miles distant from the nearest large town was based on the needs for security and safety as defined by Los Alamos' mission. Those criteria hold true even today, albeit with different interpretations.

Notwithstanding recent improvements in highway access and the growth of communities in the Rio Grande valley, the isolation that has been Los Alamos' hallmark is a major factor in the assessment of fire and emergency service needs for LANL.

Fires and their related elements require swift and decisive response if even the most limited incidents are to be contained and controlled. Resources which are hours away are of little value except for cleanup activities.

This being the case, the concept of self reliance is an essential element of fire protection planning for LANL and its environs.

\subsection{Fire Scenarios}

To help quantify the capabilities of LAFD and define the needs at LANL several round-table, discussions were held wherein the senior officers of LAFD presented the departments plans for fighting fire in specific LANL buildings. These scenarios, chosen jointly by LANL FSS-21 staff and the LAFD planning officer, were established as "benchmarks" against which the capabilities of LAFD could be measured and LANL needs defined. 


\subsection{Building No. 1/TA-43}

Building No. 1/TA-43 is approximately 100,000 square feet in size, four stories tall, with two basements. The building is located adjacent to the hospital with sharp fall-aways to the canyons on two sides.

Building No. 1 is a research facility ("The Rat Lab") with special hazards including chemicals, bio-hazards, radiation, animal and other environmental concerns.

Building No. 1/TA-43 is only minutes away from Fire Station No. 1.

In-place protections include sprinklers, alarms and detection devices and fire separations.

In an event similar to that envisioned in a Maximum Credible Fire Loss (MCFL) a fire would be detected in its early stages, contained within a series of two hour fire walls and quickly impacted by automatic fire suppression systems.

The LAFD would automatically receive the sprinkler activation signal and would, in accordance with established procedures, dispatch a first response from Station No. 1 including one pumper, one ladder truck, one rescue truck, and one medical unit. A total of fourteen (14) firefighters could be expected on scene in approximately 8 minutes whereupon, after evaluation, evacuation (search) and suppression activities would commence.

Any "smoke and fire showing" condition would result in a second alarm being transmitted, bringing on-scene resources to twenty-one (21) firefighters and officers within 16 minutes. Under these conditions, and absent any unusual complications, LAFD could provide those suppression services defined in its attack plan. There is every reason to believe that the fire would be contained within its area of origin and that losses and threats to life, property and the environment would be within acceptable limits.

It must be stressed that the basic premise of this scenario is that all systems (alarm, enclosures, sprinklers) have functioned as designed and that no unusual conditions have occurred.

The scenario presentation was carried further to discuss a variety of complications and technical difficulties which could have been encountered and which would have dramatically changed the staffing requirements for this incident.

At the outset it was assumed that injuries were not a factor. Had injuries occurred or had efforts been required to affect a rescue or rescues of persons trapped within the building, the manpower requirements would have increased significantly. Given the high occupancy of the building (over 200 people) this situation is a high probability.

Building 1 has many bio-hazards, chemical storage areas, medical gas cylinders and radiation hazards within its confines. Were these elements to have come into play, the requirements for firefighter protection and relief would have extended the time for suppression activities and thereby increase manpower requirements. 
LAFD officers estimate that any number of readily imaginable complications could raise the total staff requirement to at least fifty (50) firefighters and officers.

\section{Commentary}

Current practices by LAFD would indicate that a third alarm would bring total manpower on-site to thirty-one (31), virtually the entire on-duty force on any shift. Given the complications which might be encountered, it is possible that this building might be considered a "high risk" occupancy. If that were the case, the thirty-one (31) personnel available would not meet NFPA recommended staffing guidelines for the responding units.

Call-back procedures are such that responding personnel are usually 45 minutes away and the number of personnel available within the first hour is often no more than four (4) firefighters.

It is clear that any serious complications cause a situation which would exceed the manpower available within an hours time. LAFD would be forced to curtail its aggressive interior attack and adopt more conservative defensive strategy. In the event of a simultaneous incident, the community and/or LANL would be virtually unprotected.

\section{Building No. 132/TA-3}

As a second benchmark scenario, a fire condition was postulated in the heavily developed, critically important TA-3 complex. Building 132/TA-3 is a major computer facility designated by LANL as being of vital programmatic importance and extremely high economic value (replacement value in excess of $\$ 165$ million in four fire zones). The facility is considered a "high risk" occupancy.

Building 132/TA-3 is approximately 121,000 square feet in size, three floors in height. The facility is connected to adjacent structures by linking corridors and is in close proximity to adjacent structures. Access is restricted by security fences and adjacent buildings. This facility has automatic sprinklers throughout. There are many cable trays and large diameter cable runs throughout the building.

LAFD is of the belief that floors and fire separations are impaired by numerous unsealed penetrations and that the raised floors of the computer areas are combustible.

The LAFD pre-fire plan reflects that the computers must not be shut off. Senior officers are of the opinion that electrical service can not be interrupted (due to backup systems) and that the HVAC systems will continue to operate during a fire. LAFD believes that heavy smoke exposure will cause major damage to the computer support systems.

The scenario envisioned an after-hours (11:00pm) fire caused by an exploding transformer located in the ground level mechanical space below the main computer area. The initial explosion releases over 1,000 gallons of oil and is presumed to rupture a nearby sprinkler main thus limiting the effectiveness of the system. The assumption is made that some personnel may be in the building on late night assignments. 
Notification would be transmitted as a result of sprinklers discharge or other detection thereby initiating a first alarm response from Station 1. LAFD would have fourteen (14) personnel on-scene within 8 minutes.

A second alarm would have been transmitted on the first sign of "fire showing" thus bringing the compliment to twenty-one (21) within 16 minutes of the initial alarm. The Plan of Attack calls for aggressive interior operations which would attempt to confine the fire to the point of origin. Actions would be taken to obtain an "All Clear" and "Fire Attack" at the fire area and thereafter proceed to the upper floors with search, check and venting operations proceeding in order. These activities would proceed with an understanding that electrical power and HVAC systems would remain in operation.

Experience has shown that after normal business hours the Building Manager might not be on scene for a half-hour or more thus forcing LAFD to begin operations with only its own sources of information as to building conditions and systems.

Based on the complexity of the facility, the nature of the fire and the conditions postulated, LAFD officials project a manpower requirement, through the second alarm, of thirty-two (32), a total which exceeds the entire shift strength as now provided by LAFD. While the Community Alert Network would have been activated with a third alarm, past performance has shown that a callback response of four (4) firefighters within the first hour is typical and fifteen (15) within the second hour is typical.

Based on the LAFD evaluation of tactical requirements, a third alarm would require a minimum of fifty-two (52) personnel. Beyond the first hour of operations, staffing requirement would be a minimum fifty-nine (59) firefighters and officers exclusive of those required to attend to injuries and rescue.

\section{Commentary}

Clearly, LAFD does not currently have the on-duty staff to meet these requirements nor does it have a callback system or staffing alternative plan to allow fully effective implementation of continuous aggressive attack plans beyond the second alarm.

In the scenario postulated, and absent appropriate manpower to attack and suppress the fire in its earliest stages LAFD believes that heavy smoke would migrate throughout the building causing damage to the vitally important computer facilities. We agree.

LAFD officers believe that injuries or other complications would adversely impact fire department operations and that the community and other LANL facilities would be virtually unprotected in the event of a simultaneous incident.

The consultant team reviewed the tactical plan and while we found a certain amount of over staffing attributed to the problems with the sprinklers, we fully supported the need for at least a third alarm response. Technical complications, rescue operations and threats to nearby facilities could easily raise manpower requirements to seventy five (75) firefighters and officers. Were the fire operations to continue through a two hour period, as many as one-hundred (100) fire fighters and officers might be deployed. 
Equally disturbing was the subsequent report from LANL FSS-21 that LAFD was misinformed about the nature and status of the electrical and HVAC shutdown (and the combustible computer room floor) and had developed an attack plan which was needlessly constrained.

It should be noted that the TA-3 scenario could readily have envisioned an extension of the fire to adjacent structures, a condition which would have expanded the manpower needs well beyond those noted above.

\subsection{Needs}

\subsection{Need/General}

LANL has regulatory and policy obligations to "have access" to a fully staffed, trained and equipped fire department to assist in the protection of LANL facilities.

This aspect of need is met by the LAFD under the terms of its contract with DOE.

\section{Fire Suppression/On Duty}

On a day-to-day basis, LANL has a need for fire department and emergency medical services as a component of the overall Fire Protection and Emergency Management Programs.

Given the assumption that LANL is a "Highly Protected Risk" with a full compliment of in-place systems, history has shown that first and second alarm responses are adequate for the vast majority of day-to-day fire incidents at LANL.

The majority of LANL facilities identified as being of vital or critical priority or as having an at-risk value requiring fire department response as a part of the redundant fire protection system also are considered "high risk" occupancies as defined by NFPA. This designation (high risk) reflects situations wherein firefighting activities must take place under adverse or particularly demanding conditions. These include facilities with high fuel loading, special hazards, multiple levels, high occupancy and the like. In these conditions, NFPA recommends a higher level of staffing for individual firefighting units.

Given that most high priority facilities at LANL require "high risk" staffing and tactics by a responding fire department, we believe that "high risk" manning should be the standard for all high priority LANL responses.

Analysis of the firefighting tasks and criteria to be found at the most important LANL facilities supports a tactical plan for a two alarm response (fire and smoke showing) which would include four engine companies (a 5,000 gpm fire flow), a ladder company and a senior officer. Based on NFPA criteria for staffing in high risk occupancies, this two alarm response carries with it a need for no less than twenty-seven (27) firefighters and officers. 
Were conditions such that injuries might be anticipated (virtually any two alarm response), the inclusion of a medic unit would be indicated, bringing the total firefighter - officer component to a minimum of twenty-nine (29).

LAFD relies on the use of crosstrained firefighters arriving on medic units, rescue or other apparatus to assure appropriate staffing for firefighting assignments. A rescue unit would be part of the regular response to a two alarm incident. The staff of the rescue unit (two [2] firefighters) and the medic unit (two [2] firefighters) could be considered part of the basic twenty-nine (29) person compliment or be assigned other duties as on-site conditions dictate.

As such we find that LANL's need for firefighting personnel ready for an immediate two alarm response is a minimum of twenty-nine (29) firefighters and officers.

\subsubsection{Fire Suppression/Off Duty}

Prior experience has shown that approximately three-and-one-half $\left(3 \frac{1}{2}\right)$ firefighters and officers are needed to assure full staffing of each on-duty position over three (3) shifts. That being the case, the total staffing required for LANL is one-hundred-one (101).

\subsection{Other Services}

In addition to fire suppression activities, LANL has specific needs for other services normally provided by a fire department. These services can be provided as collateral duties with regular fire suppression activities.

LANL has determined that continued service to the Los Alamos Airport for high-hazard cargo is essential to the Laboratory's operations. This generates a need for standby CFR service.

LANL has an on-going need for standby fire department services associated with "shot activities." This and the proximity of wildlands to many LANL facilities generates a need for wildland firefighting capabilities.

LANL has a on-going need for EMS service as part of its fire department services, as a part of its emergency management program or as a highly valued services to its employees and their families in the Los Alamos-Whiterock communities.

LANL has on-site materials of such a nature and in such quantities as to make "hazardous materials" a concern in virtually every fire incident. As such, LANL has a need for highly qualified Haz-Mat response capabilities.

LANL, as with other government and large industrial facilities, may well be a target for incendiary or explosive attack. Response to that threat creates a need for the services of a qualified "bomb squad." 


\subsection{Leadership and Support}

To assure the on-going quality of the fire department services needed by LANL, an appropriate level of leadership, training and management personnel must be provided by the department providing suppression and other services.

The critical issue facing LANL is not the day-to-day occurrences but rather, it is those incidents which by all measures would be considered catastrophic.

Natural disasters, incidents precipitated by explosions, deliberate incidents, incidents with major systems failures, simultaneous incidents and incidents with far reaching environmental effects are within the realm of possibilities readily envisioned at LANL.

While history has shown that such incidents (at LANL or at its sister institutions) are few and far between, the risks associated with such events are of such magnitude, and have so great an impact, as to require planning and resources appropriate to that challenge.

In the true sense there can be no absolute measurement of the resources which should be available to meet the challenge of a catastrophic event. It is possible, however, to obtain a certain point of comparison, when one looks at those fire department resources readily available at other institutions.

While most DOE facilities have limited "on-site" fire departments, they have ready access to nearby municipal departments available for response to major incidents.

By way of example, when wildfires recently erupted in the vicinity of Brookhaven National Laboratory, nearly two-thousand $(2,000)$ firefighters were assembled from over one-hundred-seventy-five (175) well equipped fire departments within a one-hour travel distance.

Argonne National Laboratory has virtually the entire Chicago Fire Department (over 3,000 firefighters) at its doorstep. Other DOE facilities within close proximity to established municipal areas have support resources ranging in size from one-hundredfifty $(150)$ to two-thousand $(2,000)$ personnel.

LAFD Chief MacDonald estimates that even in the most dire situations no more than seventy-five (75) firefighters would be available from the ranks of the department.

The review of fire scenarios conducted as part of this study demonstrated a need for a compliment of fifty-nine (59) firefighters and further indicated that any large scale systems failure, significant technical complications, mass casualties or simultaneous incidents could readily require the commitment of one-hundred (100) firefighters to the first two hours of a major incident. This two hour period is coincidental with the most critical period of a fire response and marks the most optimistic time estimate for large scale assistance from beyond the immediate Los Alamos area. 
Given the potential risks and the levels of fire department services found at other DOE facilities, it is our belief that LANL has a need for no less than one-hundred-fifty (150) firefighters available to respond in the event of a major incident.

4.6

\section{Community Needs}

The goal of this study is to define LANL's need for fire department services. As such the identification of services and manpower noted previously are those deemed necessary to meet LANL's requirements regardless of any collateral obligations in the community.

We would be remiss, however, if we did not again call attention to LAFD's dual responsibilities for service to LANL and the community. It is our opinion that as a minimum, LAFD should be able to serve LANL's needs (two alarms) and still have at least one engine company and one medic unit available to serve the community in the event of a simultaneous incident. 


\section{Conclusions}

An evaluation of the regulatory and policy requirements governing fire protection at LANL, a review of the conditions to be found at LANL, LAC and LAFD, and an analysis of the fire department services needed by LANL to meet its objectives results in the following conclusions.

\section{LANL Fire Protection}

The overall level of fire protection at LANL has declined in the past three years due to a combination of cost reduction policies, new initiatives and the general ageing of facilities and systems.

All indications are that this trend will continue, thereby increasing the likelihood and potential severity of fires in LANL facilities or on its grounds.

\section{Self Reliance}

The significant perils and critical importance of the facilities and programs to be found at LANL lead to the inescapable conclusion that emergency responses must be swift and appropriate to the threats found at the Laboratory.

The geographical isolation of LANL is such as to make self reliance for this initial response an overriding concern in the planning of fire defenses.

\subsection{Fire Department Services}

Fire department services are an integral component of the Fire Protection Program mandated for all DOE facilities and developed by LANL. These services must include the capacity for fire suppression and support activities including emergency medical and hazardous materials incident response.

As a minimum, immediate fire department response to a fire incident of two alarms for high risk occupancies is essential for the day-to-day requirements of LANL. This requirement generates a need (LANL only) for at least one-hundred-one (101) full-time firefighters of whom at least twenty-nine (29) would be on duty at any shift.

In addition to the day-to-day requirements for fire and emergency services, LANL has an undeniable need for fire department services equal to the task of defending public safety, minimizing environmental damage, protecting government property and programmatic continuity in the event of a catastrophic incident at LANL.

As a minimum, a total available compliment of one-hundred-fifty (150) firefighters are necessary to provide a credible response for major incidents at LANL. 


\subsection{Los Alamos Fire Department}

LAFD has markedly improved its capabilities, particularly in the areas of organization and management, training, utilization of resources, pre-fire planning and physical conditioning.

Notwithstanding these improvements, there remain serious shortcomings in terms of LANL-specific training, wildland firefighting capabilities and recall of off-duty personnel.

Most importantly, LAFD does not have the current capacity to undertake simultaneous fire fighting responsibilities at LANL and/or the community, nor does LAFD have the current capacity to undertake aggressive firefighting for major incidents at LANL (beyond two alarms) or those with significant technical complications.

To meet LANL's need for defense against major fire incidents LAFD must have a trained manpower reserve of at least one-hundred-fifty (150) personnel "on-call" to assure a credible and appropriate response.

5.0 Major Loss Risk

Evaluation of the factors noted above leads the consultants to the central conclusion that LANL stands at significant peril from the threat of fire.

LANL's reduced level of fire protection combines with the current limitations and shortcomings of LAFD to make major losses a distinct possibility.

In the event of a major incident, the conditions now existing have no other interpretation but that LANL is a risk for a catastrophic loss. 


\section{Delivery Options DOE Fire Department}

On its face, one might consider the question of a needs analysis for DOE fire services to be moot. The need for a fire department was established by DOE, DOE has provided the fire department (LAFD) ergo, the need is, by definition and inference, satisfied.

It is our belief, however, that prudent management and both the spirit and letter of DOE 5480.7A requires LANL to be proactive in the evaluation and definition of the fire department services which it (LANL) deems appropriate to meet the fire protection objectives established for the facility.

Should DOE continue to provide fire department services to LANL we suggest that the standards and recommendations herein be the basis for those services and that LANL support those standards in the strongest possible terms.

\subsection{In-House Fire Department}

It is possible to have the University of California create a full-time LANL-based "fire department" or "brigade" which would be organized, trained, equipped to provide the level of professional services which is indicated by the risks at LANL.

However, given the liability which is inherent with "in-house" fire brigades, the requirements for expanded capacity in the event of a major incident and the ad-hoc nature of this approach, we believe that "in-house" firefighting forces are a less than satisfactory option.

\subsection{Contracted Services}

It is equally possible for LANL to retain a private contractor vendor to provide fire department services at LANL. Professionalism should be the yardstick by which any such service would be measured. Johnson Control International and other "private" fire department companies could readily offer proposals for the services LANL requires. Were this option to be chosen, we have little doubt that a successful contractor could offer the same services to Los Alamos County as an alternative to the existing Los Alamos Fire Department service.

In essence, LAFD functions much like a "contractor," with Los Alamos County providing the operational services, in return for payment by DOE. While we are mindful of the historical commitment on the part of the federal government to provide fire department services to Los Alamos County until some ill-defined level of "self sufficiency" is achieved, and we are fully aware of the on-going negotiations between LAC and DOE on the issue of "self sufficiency," we view the current situation as needlessly convoluted and detrimental to cost-effective fire department and emergency medical services. We certainly hope that this system will be revised in the near future.

County Administrator Georgieff has indicated the County's strong interest in providing fire department and emergency medical services under a direct contract with LANL. 


\subsection{Recommended Option}

While the selection of fire department service modes may depend largely on an evaluation of costs, we believe that an analysis of liability factors, technical requirements and its own institutional focus will lead LANL to favor "contract providers" (either private or Los Alamos County) if DOE moves to restructure its own role as a provider of fire department services. 


\section{Recommendations}

Definition of the level of the day-to-day fire department services required by LANL and the evaluation of the appropriate methodology for the delivery of those services can best be achieved by an analysis of the critical components of fire department services in the light of the conditions under which those services will be provided.

There may be no credible method to quantify those services needed should a catastrophic incident occur, especially one which could have consequences far beyond LANL boundaries. There are, however, steps which can and should be taken which will provide a more reasonable and effective response to such an incident, should it occur.

To these ends we offer the following observations and recommendations for meeting LANL's needs. The recommendations are grouped in accordance with the Scope of Work developed by LANL for this report.

\subsection{Organization and Management}

\subsubsection{Reemphasize the importance of fire protection as a critical element of the comprehensive safety and emergency management efforts at LANL.}

From the outset of our involvement with LANL and DOE it has been all too evident that fragmentation of efforts and failure to see the big picture has been a heavy burden on the fire safety program intended to serve both LANL and the Los Alamos Community.

In the course of our initial study we found evidence of cross purposes between DOE, LANL, LAFD and LAC. We found misconceptions as to organizational focus and poor integration between LAFD and LANL on matters relating to fire and emergency services. These issues were repeatedly raised with our client (DOE) and, indeed, a significant improvement has been achieved. Nevertheless, it is clear to this consultant that there remains a long road ahead to reach a level of cooperation and integrated fire services as are mandated by the risk potential at LANL.

As it applies to LANL, we have not found clear indications that fire is adequately recognized as a threat to the institution, its mission and its surroundings.

We find little evidence to indicate a recognition that fire can be a formidable weapon in the hands of the malcontent or ill intentioned.

We have found anecdotal evidence to indicate that fire safety is often measured from historical rather than a forward looking perspective ("we haven't had many fires...therefore we don't have to worry much about them").

We have found well developed programs devoted to facility safety, maintenance, security, medical care, communication, community interaction, inter-agency relations - but fail to find the kind of inlegrated approach that would lead to the conclusions that everything would pull together in the event of a major emergency. 
We find the focus on cost reduction to be so pervasive as to give an outsider the distinct impression that fire safety has been relegated to a secondary consideration.

We urge, in the strongest possible terms, that the threat of fire be recognized in all its potential and that fire defenses be fully integrated into the comprehensive emergency management efforts at LANL.

1.0.2 Fire Department services should be provided by a single, highly professional entity.

The collective perils, the concentrated assets, the critical importance and the geographic isolation to be found at Los Alamos have combined to create conditions which, in our opinion, are unique.

In the belief that extraordinary risks demand maximum preparedness, we see no justification for anything but a professional fire department as a critical component of the Fire Protection Program at LANL. While we have a high respect for those dedicated but less formal organizations which protect many areas, we believe that the LANL's need for swift, aggressive and technically appropriate action on the part of a responding fire department can only be met by a cadre of professionals whose primary focus is firefighting.

The same need for swift and decisive action and the previously stated recommendations for an integrated management system which includes fire department, emergency medical and haz-mat services, leads to the inescapable conclusion that a single entity would be the most appropriate vehicle for the delivery of these services at LANL. Analysis of the day-to-day workload for fire and emergency services in Los Alamos County and at LANL clearly indicates that a single entity is adequate for the task and could be more effectively trained for multi-task responsibilities.

\subsection{Personnel}

\section{Personnel/On Duty}

\subsection{1}

\section{The on-duty personnel immediately available to provide first and second alarm response to LANL should be no less than twenty-nine (29) firefighters and officers.}

DOE and LANL have recognized NFPA standards for fire department operations.

NFPA 1500 recommendations for response to the type of high risk occupancies found at LANL include first line pumpers with a five (5) person crew, and ladder trucks with six (6) person crews.

NFPA standards further recommend the response of emergency medical services to all incidents where injuries might be expected. New Mexico State regulations and NFPA standards dictate a minimum crew of two (2).

Based on tactical considerations and generally accepted practices, a two alarm response for high risk occupancies such as are found at LANL would include four (4) engine 
companies, each with an enhanced crew of five (5); a ladder company, with an enhanced crew of six (6); a medic unit with a crew of two (2); and a senior officer. In total, a full two alarm response would require a minimum of twenty-nine (29) firefighters and officers.

Whether the additional staff required by the high risk occupancy arrives as part of the engine and ladder companies or as part of a responding rescue unit is a tactical consideration best left to on-scene commanders.

\subsection{2}

To assure the required first and second alarm response to LANL on all shifts, the fire department providing services must have a full-time compliment of at least one-hundred-one (101) firefighters and officers.

Based on requirements for holidays and vacations, sick and personal days and regular on-duty/off-duty hours, a multiple of three-and-a-half times the minimum duty strength is required to cover three regular tours.

2.1.3 To assure an appropriate level of management, training and leadership, the fire department providing services must have a full-time command and support staff as recommended by NFPA standards.

Well managed, well trained and well directed fire departments require an effective and well motivated command structure.

We recognize the possibility of combining certain staff functions with regular line assignments. We are equally aware that in any major incident, all available staff including administrative officers, will respond to the fireground.

We caution, however, that overlapping and coincidental responsibilities have limits and recommend that LANL be wary of attempts to downgrade or eliminate valid administrative and command positions from the fire department roster.

\section{Personnel/On Call}

\subsubsection{Provide a fully trained On-Call Reserve of one-hundred-fifty (150)} personnel.

Perhaps the most vexing aspect of an evaluation of fire department services is that associated with major incidents where maximum efforts are required at LANL.

Evaluations conducted during the course of this study indicated that while LAFD is capable of providing an appropriate response to a straight forward first and second alarm fires where in-place systems function as designed, high hazard incidents, or any significant complications including but not necessarily limited to multiple casualties, system failures, or simultaneous incidents are beyond the capabilities of LAFD on-duty personnel as now provided. 
It is further evident that call-back times for LAFD personnel are often in excess of an hour and may not result in the assembly of adequate personnel to effectively attack and sustain operations for a major fire incident where personnel demands could reach one-hundred-twenty-five (125) firefighters and officers within a two hour period. LAFD could not count on meeting much more than half of that total from its on-duty and recallable staff, even under the most urgent recall conditions.

Efforts to develop effective mutual aid agreements have proven illusive. Response times by supporting elements from surrounding fire services are so long as to be of little value in the event of a large and fast-moving fire.

It is our belief that the most effective approach to the need for personnel in the event of a major fire incident lies in the formation of an On-Call Reserve of fully trained, properly equipped firefighters who would be deployed under the command of the LAFD leadership.

Past experience has shown that the total strength of an On-Call Reserve should be double that which might be required at a specific incident. Prudent judgement and the standards of protection at other $\mathrm{DOE}$ facilities would indicate a total staffing requirement at a major incident of one-hundred-fifty (150) of which seventy-five (75) might be full-time LAFD personnel, with the remaining being On-Call Reservists. To meet that requirement, the total On-Call Reserve should number approximately one-hundred fifty (150) personnel to assure available manpower at all times.

The manpower for an On Call Reserve could be drawn from greater Los Alamos, both the community and LANL so as to be readily available in the event of an incident. LANL management should actively encourage and support such a program for its employees and subcontractors. Emphasis should be placed on the recruitment of LANL employees with security clearances and special skills such as Haz-Mat or bomb disposal.

While the mutual interest of community residents and LANL personnel might well foster a volunteer response, we believe that commitment required for training and readiness would justify appropriate hourly compensation for members of an On-Call Reserve.

Detailed cost estimates are well beyond the scope of this study. Nevertheless, we can suggest that the basic training costs for On-Call Reservists would be on the order of three-thousand dollars $(\$ 3,000)$ per man. After this initial start-up expense, on-going costs for monthly training might be on the order of one-thousand-five-hundred dollars $(\$ 1,500)$ per year. The cost of security clearances would probably be low if, as expected, the bulk of an On-Call Reserve is recruited from current LANL employees.

Reservists should have training and equipment equal to that of full-time Fire Department personnel.

Communications systems should be devised to quickly activate On-Call Reservists in the event of a major incident. 
2.2.2 LAFD should expand efforts to improve call-back times for off-duty personnel.

In the course of the study it was reported that fully $80 \%$ of LAFD personnel live "off the hill." As a result, call back times often exceed an hour, effectively limiting returning firefighters to mop-up roles in any fire incident.

While the situation may be outside of the LANL sphere, LAFD should be encouraged to recruit from within the community and should investigate methods such as preferential hiring and housing supplements to insure more rapid recall times for off-duty personnel.

Technical support (pagers etc.) should be enhanced to further improve recall times.

\section{Location of Fire Stations/Response Time}

\section{Three fire stations are necessary for LANL at this time. This condition should be reevaluated as facilities are reconfigured.}

The location of fire stations is driven by the need to provide response times within acceptable limits.

Our earlier study indicated that Stations 1,3 and 5 were situated so as to allow initial response times within the parameters established in the SAR's for various LANL facilities. Indeed, there was an indication that full-time staffing of Station 5 might be curtailed if activities in TA-16 were reduced.

Recent analysis of the expanded and anticipated programs at TA-16 would suggest that it is premature to consider deactivation of Station 5. We suggest that this issue be revisited as development plans unfold.

Station 3 (White Rock) serves the Pajarito Road corridor including TA-54. Continued development (and planned facilities) in this area will increase the importance of Station 3 in the Fire Protection Program.

As was indicated in the initial study, Station 3 is less than satisfactory in space and configuration. The site is limited in size and flexibility. It may prove cost effective to replace rather than remodel Station 3. Were that to be the case, a site closer to TA-54 would be to LANL's benefit. LANL might do well to identify such a site within its own boundaries.

While standby response to the airport can be scheduled from any fire station, the response to facilities on DP Road (TA-21) should be evaluated to see if Station 1 could meet the criteria.

It may be necessary to consider Station 6 as being essential to LANL's fire department services need, at least until the decontamination and demolition of facilities at TA-21 is completed. 


\subsubsection{Re-evaluate response times in the light of changing access} conditions.

While the response times to facilities in outlying TA's had been found to be within acceptable norms in the earlier study, we are concerned that newly instituted security procedures at a number of LANL sites has (and will) significantly impede access thus effectively increasing firefighters response time to the location of a fire.

The added minutes required to get past a locked (and untended) security gate could allow a relatively minor fire to reach major dimensions and thereby increase the danger to firefighters, the facility and its surroundings.

Cost benefit and risk analysis should be part of any LANL decision to introduce barriers to emergency access.

\subsubsection{Standardize the guidelines for accessibility. Provide information} to LAFD on procedural changes.

The Facilities Management approach now being implemented at LANL carries with it the risk of widely differing conditions affecting fire department services. While we appreciate the value to be found in localized, results-oriented management, we caution that the multiplicity of conditions which arise from differing managerial perspectives and priorities will adversely affect firefighter operations.

We urge that issues relating to fire protection and firefighter access be standardized to the greatest practical degree.

\section{$2.4 \quad$ Apparatus}

\subsubsection{Fire apparatus should meet NFPA guidelines and be appropriate} to LANL needs.

Notwithstanding some technical shortcomings with respect to NFPA standards, the first-line LAFD equipment is generally adequate to most LANL requirements. As replacement units are provided, LANL should insist that all aspects of NFPA standards be met and that site-specific consideration be given to the selection of equipment.

By way of example, we were encouraged to see that Ladder 1 is now a part of regular assignments. It was also encouraging to find that LAFD had "traded" a single heavy rescue unit for two more flexible light rescue units.

It was disturbing, however to hear that two reasonably useful reserve units (Engine 50 and Tanker 50) were removed from service because funds were not available for mechanical repairs. We believe this to be shortsighted and suggest that these units could readily be made available to an On-Call Reserve.

Returning to the issue of task-specific apparatus we note that none of the LAFD equipment meets NFPA standards for wildland fire fighting, a condition we find to be of serious concern and will discuss in more detail in that section of the report. 
2.5

2.5 .1

2.6

2.6.1

2.6.2

2.7

2.7.1

2.7.2

\section{Alarm Response to LANL Leased Spaces}

\section{LAFD response to LANL leased structures should be consistent with those of other community facilities.}

We found no reason to believe that fire department response to "in-town" sites was anything other than that which was typical for other non-LANL properties. We do call attention to the fact that safety standards for leased spaces are not necessarily equal to those which are found on LANL grounds.

\section{Communications and Dispatch}

\section{Centralized communication and automated dispatch of fire department services is strongly recommended.}

Recommendation for a central communication and dispatch system for LAFD was strongly stated in our initial study for DOE. It was disturbing, therefore, to find that such a system was thoroughly researched and detailed proposals were developed only to be scrapped in a cost-cutting move. The need remains and the technology is available. We urge all emergency response organizations in Los Alamos (both LANL and LAC) to press for the implementation of this system and suggest that from LANL's perspective, relief from the potential liabilities now carried by the Laboratory might of itself, be worth the cost.

\section{Emergency communications system should allow the most effective communication by all agencies.}

As a continuation of the recommendation for a centralized communication and dispatch facility we take note of the difficulties to be encountered when multiple agencies attempt to communicate on disparate systems. LANLshould encourage and participate in efforts to create a closely integrated emergency communications network for LAFD and those other agencies which might be expected to respond to emergency incidents.

\section{Property and Equipment Maintenance}

\section{LANL should insist that LAFD comply with NFPA and manufacturers recommended standards for the maintenance of firefighting equipment and apparatus.}

Unreliable equipment is an invitation to serious consequences.

\section{LANL should maintain its own "equipment" to the highest level of reliability.}

In the course of this study we were more concerned with indications that the reliability of LANL fire protection systems had been lessened than we were with almost any other aspect of our investigations. 
Our 1992 evaluation of the need for fire department services was anchored by the assurances made by both DOE and LANL that LANL was a "Highly Protected Risk" with exemplary in-place systems, the reliability of which was unquestioned.

Returning three years later we find that basic assumption less than solid, a condition which, if true, can lead to losses the likes of which make arguments over the cost of a few firefighters pale to insignificance.

We have been advised that the resources available to develop and maintain critical fire protection systems (alarms, sprinklers, detection devices, fire doors and dampers) have been reduced in real-dollar terms. As evidence of this, the number and seriousness of false alarms and system outages have increased, as have downtimes for system components.

Of particular significance, maintenance work is being concentrated on a few buildings with "critical" importance, thus reducing the overall level of attention given to other buildings.

The increased emphasis on "compliance and documentation" is drawing an ever-increasing portion of the limited maintenance resources.

Funding cut-backs have lead to wholesale elimination of certain preventative maintenance procedures. Likewise, reductions in the security staff have reduced the level of "eyes on the scene" patrols thereby leaving fire discovery more to chance or automated systems which themselves are less reliable due to limited maintenance.

Programs which might be expected to enhance fire safety (removal of decommissioned structures, upgrade in water distribution systems and the like) have been slowed thus exposing LANL to risks well beyond those found in prior years.

New program initiatives and new facilities are started with a mindset, from the standpoint of fire protection, of how cheap?, rather than how good?. By way of example we point to the array of temporary buildings and trailers, any one of which could be lost in a fire which could, in turn, readily spread to many similar structures parked side by side throughout the institution.

The reported efforts to avoid in-place fire protection for flammables, pyrophorics, oxidizers and hazardous wastes accumulated at TA-54 is evidence to this consultant of a change in mindset which places cost containment and other considerations above safety.

While such expediency may have been justified in the days of the Manhattan Project, we find it shocking, given the risks and the stated policies of DOE and LANL, that the commitment to fire safety appears to have diminished.

Of any recommendation we make, the most important is that the commitment be reevaluated and returned to its high priority. 


\section{Training/Pre-fire Planning}

We have chosen to link these two issues since, from the end-users perspective (LANL's) the dual aspects of "preparedness" are part of the same concern.

\section{Pre-fire planning for incidents at LANL should be site-specific and particularly attuned to the conditions to be found at the Laboratory.}

We were encouraged to find that in the years since our initial report LAFD had markedly improved the intensity and breadth of training afforded its firefighters and officers. LAFD reports a degree of cross training and specialized certification which goes a long way toward maximizing the effectiveness of its forces.

We were equally impressed with the strides made in pre-fire planning for incidents at LANL (and in the community).

We were seriously disturbed, however, by indications that specific on-site conditions were not adequately recognized nor were provisions or procedures in place for dealing with the unique hazards to be found at LANL.

By way of example we point to a roundtable discussion which focused on a potential fire condition at TA-55/PF-4. While LAFD was well aware of the various hazards in the building and had good diagrams showing water sources, access points, staging areas and the like, the senior LAFD officers were unaware that defending the HEPA filter system and preserving the building enclosure was critical to preventing a potentially catastrophic plutonium contamination of LANL and/or the entire community in the event of a serious fire.

The benchmark fire scenario developed by LAFD for Building 132/TA-3 had a fire attack plan which presupposed conditions (no electrical shut-off, no ventilation shutdown) which were at variance with fact. Given the likelihood of a delayed arrival by the Building manager, the initial fire operations would have been needlessly hampered.

Turning to yet another condition, it was reported that changing hazard evaluation information frequently fails to be effectively imparted to LAFD. As an indication of this situation, we were advised of a recent incident wherein a hazardous cargo of significant size was landed at Los Alamos Airport with little or no information being passed on to the CFR crew on standby duty.

Assessment of each and every hazard condition is beyond the scope of this report - and beyond the security clearance of the author. It is clear, however, that LANL has the technical expertise necessary to guide LAFD in making the critically important tactical decisions in any fire incident. Only LANL can define those elements of programmatic importance whose loss or damage would be devastating to the Laboratory's operations. It is equally clear that such information has not been effectively communicated to LAFD for incorporation in the pre-fire plans for LANL facilities. There is an indication that even the limited information which does get transmitted to LAFD administration often fails to be effectively communicated to those firefighters and officers who would be first on the scene and most active in the initial fire response. 
This communication and interaction is essential to the success of any successful firefighting effort.

2.8.2 Training for LANL fire incidents should include comprehensive drills under realistic conditions.

We are aware that fire department familiarization tours have been conducted at many LANL facilities. We are equally aware that occasional false alarms often give LAFD personnel an opportunity to test response times and deployment practices. We do not find, however, that LAFD (and LANL emergency response personnel) conduct regular drills designed to test theoretical pre-plans and hone those skills which would be required in the event of an incident.

We note further our earlier recommendation to DOE that where actual workload is low a rigorous schedule of simulations is the best method to keep skills sharp and avoid institutional boredom.

LANL should encourage and participate in these exercises as a critical component of its Fire Protection Program and a meaningful demonstration of readiness on the part of LAFD.

\subsubsection{Pre-fire planning for all significant LANL facilities should be} completed and should include additional information.

The good efforts underway should be completed and kept current as an essential part of the LANL fire defense effort.

A review of the LAFD pre-fire planning documents indicates that they lack certain information which would be essential in fire conditions. Data on the structural system, fire subdivisions and key mechanical-electrical controls would be important additions.

A brief description of the site-specific hazards (more than just a listing), identification of programmatically important areas and information on safety concerns should be included in pre-fire documents.

Consideration should be given to providing such information as can be distributed within security confines on a computer network available to on-scene fire commanders.

$2.9 \quad$ Hazardous Materials Incident Response.

2.9.1 LANL should serve as a technical resource to the LAFD and New Mexico State Police in the event of Haz-Mat incidents within the community.

New Mexico law designates the State Police as incident commanders for Haz-Mat occurrences outside of federal facilities. As a practical matter, Haz-Mat incidents "in the community" are very likely to involve LANL material in transit. Given the response time for State Police personnel it is clear that local forces will bear the brunt of initial Haz-Mat activities. 
The high probability of a "shared interest" and the specialized expertise to be found at LANL, make it obvious that LANL should be primed to offer its assistance in any Haz-Mat incident.

The LANL explosives and radiological response units should continue as resources available to respond as needed.

2.9.2 LAFD should provide Haz-Mat response to LANL.

LAFD has completed Haz-Mat training for its personnel to the level where they are a valuable asset. Notwithstanding the State of New Mexico Haz-Mat response plan which assigns incident command to the first arriving State Police officers, the isolation of Los Alamos is such that LAFD is often in charge of activities during the critical initial phase of an incident.

We believe that LANL should draw on this strength and call upon LAFD to provide primary Haz-Mat response to the Laboratory. We believe that LAFD could undertake much of the Haz-mat response duties as a collateral assignment with little required in terms of manpower other than ad hoc assignments from an On-Call Reserve.

We recognize that such a decision would require a renegotiation of the LAC/DOE contract to cover the cost of training, equipment and On-Call personnel. Such a renegotiation would undoubtedly result in some manner of pass-along cost to LANL. Nonetheless, we believe that the cost savings and relief from liability to be realized by LANL would more than justify such a renegotiation.

LANL should continue to provide the special technical expertise for those Haz-Mat incidents which are specific to its own operations.

\subsubsection{LAFD should provide "bomb-squad" services to LANL and the community.}

LAFD could readily develop the expertise needed to provide "bomb squad" services to the community and, in all but certain unique instances, to LANL.

While LANL may be the only reasonable provider of such services when weaponry and special nuclear materials are involved, most other incidents involving incendiary and explosive devices could be shifted to LAFD. Such a service could be undertaken as a collateral responsibility, using ad hoc personnel from an On-Call Reserve.

As with Haz-Mat services, such an arrangement would require renegotiation of the LAC/DOE contract. It is our belief that the cost savings and the relief offered from the liability LANL now carries would more than offset any pass-along expense. 
2.10

2.10.1

\section{Wildland Fires}

\section{LAFD should have authority and adequate capacity to mount an effective initial defense against wildland fires which threaten LANL facilities.}

In the course of our earlier study we were advised by DOE that the mission of LAFD was limited to structural fighting in the wildland/suburban interface and that wildland fire fighting capabilities were to be provided by "other" agencies.

We believed then, and continue to believe now that the geographic isolation of LANL coupled with the proximity of many LANL facilities to wildland areas combine to make rapid response to wildland fire a vitally important aspect of fire department services.

During the course of this study we were given what we now understand to be a rare opportunity to over-fly LANL and view the relationship of wildland and buildings from above. The conclusions to be drawn are unmistakable: be prepared to effectively attack wildland fires in their very earliest stages or suffer the consequences.

The La Mesa fire in 1977 gave a frightening demonstration of what could happen when nature takes its course. Today, with unoccupied but still hazardous buildings dotting the forested landscape and with LANL facilities built to the edges of heavily wooded canyons the potential for a major loss is high.

LAFD reports that wildland fire fighting support from Bandelier and Santa Fe National Forest is more than several hours distant and often consists of no more than 6 or 8 people. The mutual aid agreement with the La Cueva Fire Department, a respected wildland firefighting organization, presupposes a nearly 50 mile drive and is farther limited by the fact that many of the La Cueva firefighters are LANL employees. Returning to La Cueva to gather equipment and apparatus would require a round-trip in excess of three hours.

LAFD has completed wildland firefighting training to the bulk of its forces. LAFD has developed a small scale response force (a nine [9] member EAT Team). What is lacking is a authority and large scale capability to attack and block a wildland fire while larger, more specialized forces are assembled.

LAFD has no firefighting apparatus geared to the rigors of off-road wildland firefighting. While several units are able to utilize compressed air foam (CAF) that capacity is limited. The recent roll-over of a tanker is further evidence of the unsuitability of LAFD apparatus to a wildland fire mission.

A high priority should be assigned to obtaining appropriate off-road equipment and expanding the wildland capabilities and responsibilities of LAFD.

2.10.2 LANL should identify and keep current an inventory of equipment which may prove valuable in the event of wildland fire activities.

As the busiest construction site in the County, LANL is often the location of significant resources in heavy equipment. This information should be readily available to LAFD 
and procedures should be in-place to call on these resources if needed to fight wildland fires.

2.10.3 Prescribed burns should be undertaken as a preventative measure.

We are mindful of the impact of conservation and preservation regulations governing many sites at LANL. Nevertheless, we believe steps should be taken, particularly at "shot sites" to remove accumulated fuel and thereby limit the wildland fire potential.

2.10.4 Abandoned or decommissioned structures should be removed from woodland areas with dispatch.

The tasks of decontamination and demolition are important components of the overall fire protection plan. Those structures in woodland areas present added problems as "attractive nuisances" and being vulnerable to wildland fires. Removal efforts, particularly for contaminated structures, should be given a high priority.

\section{Mutual Aid}

\subsubsection{Encourage mutual aid agreements but do not rely on those} agreements to satisfy LANL's need for fire department services.

The tradition of and value to be found in the concept of Mutual Aid is solidly rooted in the fire services.

Recognizing that fire department services are marked by long periods of "stand at the ready" punctuated by short intervals of frantic "all hands" activity, communities across the land have looked to mutual assistance as the best course of action to balance the needs of day-to-day protection, major incident response and cost effectiveness.

To the extent that fire services outside the Los Alamos Fire Service Area have a shared interest in firefighting and given the high level of professional manpower, training and equipment to be found in the LAFD, it would seem, at first glance, that mutual aid agreements would be readily developed between LAFD and its sister agencies. Indeed, the DOE/LAC contract stresses this approach.

As a practical matter, however, the concept of mutual aid as it is generally recognized is of little value to LANL as it considers its needs for fire department services.

LAFD can not count on more than 4 to 6 of its own off duty firefighters returning to an emergency callback within an hour. What then, can be expected of a call to an all volunteer department whose base of operation is more than an hour (sometimes 2 hours) away?

In the course of this study issues have been raised about the compatibility of equipment (Santa $\mathrm{Fe}$ ) and the training levels of various volunteer organizations. We believe that these issues can be addressed given time and funds. With that in mind we endorse all efforts to expand mutual aid agreements with neighboring departments and with those agencies whose special services may not be available elsewhere. 
The real question with mutual aid agreements goes to the availability of assistance within a time span such as to make that aid valuable to LANL in the event of a fast moving major fire.

Given the nature of the fires which might be anticipated and given the distance even the closest of neighboring units must travel, we believe that LANL should not place great reliance on "mutual aid" as a significant resource in evaluating the strengths and capabilities of LAFD.

Emergency medical services are an integral part of fire department services as provided by LAFD and, by and large, by fire departments across the nation.

Typical of many fire departments, LAFD relies on cross-trained firefighters/EMT's to give fire commanders the flexibility to assign manpower as conditions dictate.

As one of the high points in our revaluation of the capabilities of LAFD we found the extent of training and certification for cross-trained personnel to be outstanding. We note further that emergency medical services are a very high priority within the community. We expect this situation to grow, especially as the community matures. LANL personnel are the community. The importance of competent and comprehensive EMS is of great value to LANL employees and their families.

Given the high quality of the available resources, the flexibility to be gained from cross-trained EMT/firefighters, the importance of the service to LANL staff members and their families, the speedy response provided by community based ambulances and the potential for serious incidents at LANL we recommend that Emergency Medical Services be retained as a primary function of LAFD.

\subsubsection{Transportation capabilities for mass casualty incidents should be} developed.

The potential for mass casualty incidents at LANL is obvious. Emergency planning activities often postulate a significant number of injuries arising from incidents which are readily envisioned.

While LAFD has a large number of trained EMT personnel, the transportation capabilities as represented in four ambulances is totally inadequate to what major incident needs might be. Given further that the capacity of Los Alamos Medical Center to deal with major trauma incidents is over taxed at four (4) cases, the need for more long distance transportation capability is readily apparent.

DOE has recently suggested transferring EMS responsibilities to private providers. As noted above we believe that EMS is best provided by the LAFD. There is reason to believe, however, that private contractors could undertake much of the long distance transportation functions and thereby provide additional capabilities in the event of a major incident at LANL. 
2.12.3 LANL should provide services in the areas of firefighter physical examinations, fitness and wellness.

We were encouraged to find that LAFD had improved its level of physical fitness and had raised the level of attention given to the physical conditioning and health maintenance of its personnel.

We were equally impressed with the well established programs and facilities LANL has in the areas of industrial and occupational health, employee physical examinations and wellness.

We see these services as on-going efforts at LANL and suggest that in offering similar services to LAFD, economic benefits would accrue to each organization.

2.13.1 Building inspections should be undertaken by LAFD in concert with LANL

Familiarity with potential fire sites is a valuable aspect of effective pre-fire planning. Traditionally, one of the most effective ways to increase "familiarity" on the one hand and improve overall fire safety on the other, has been to involve firefighting personnel in the building inspection process.

We recommend that LAFD personnel be involved in regular building inspections at LANL. While this is not intended to replace in-house inspectors, such activities will serve to support LANLstaff and greatly improve LAFD's understanding of the workings of individual structures.

\section{$2.14 \quad$ Acceptable Loss}

(Text In Earlier Sections)

\subsection{Development of Operational Procedures}

(Text In Earlier Sections)

\subsection{6} Airport Crash/Fire Rescue Service

Regularly scheduled flights (Ross Air) into Los Alamos Airport were suspended after October 1st 1995. Peacock Air Service is now providing limited service to Los Alamos, the details of which are being developed at this time. Given the "grandfathered" nature of FAA certification for the Los Alamos Airport the decision to keep LAFD CFR capabilities in place is a wise one.

LANL has indicated that the capacity to bring vital shipments into the airport is essential to LANL's operations. As such, the need for standby CFR capabilities remains, regardless of the station of regularly scheduled passenger service. 


\section{Needs Assessment Update}

To assist the reader in evaluating current conditions underlying this report the following comments and notes are provided as an "update" for the 1993 FIRE DEPARTMENT NEEDS ASSESSMENT prepared for DOE by Beatty, Harvey and Associates/International Fire Consultants, Inc.

The subject headings and enumeration are those which were found in the 1993 Assessment. Where conditions have little or no bearing on the current need for fire department services at LANL the term "no significant or applicable comments" has been utilized.

The readers attention is called to the fact that the comments relating to the Los Alamos Fire Department (Section 2.0) were provided by LAFD during the course of our interviews. 


\section{Introduction}

1.0 Overview

1.1 Background of the Study

No significant or applicable comments.

1.2 Goals and Objectives of the Study

No significant or applicable comments.

1.2.1 Goals

No significant or applicable comments.

1.2.2 Objectives

No significant or applicable comments.

1.3 Study Team

No significant or applicable comments.

1.4 Methodology

No significant or applicable comments.

\subsubsection{References}

No significant or applicable comments.

1.4.2 Data Gathering and Evaluations

No significant or applicable comments.

2.0 Fire Department Services Agreement

No significant or applicable comments.

3.0 Fire Service Area Description

No significant or applicable comments. 
3.1

3.1 .1

3.1 .2

3.1 .3

3.2

3.2.1

3.2 .2

3.2 .3

3.2 .4

3.2 .5

3.2 .6

\section{Los Alamos National Laboratory (LANL)}

\section{Background}

On-site LANL facilities are noted in the '95 Institutional Plan as approximately 7.6 million s.f. Leased facilities are approximately 180,000 s.f.

\section{Population}

A reduction in staff of as many as one-thousand $(1,000)$ is being considered. An earlier downsizing had reduced total population slightly.

\section{Facilities}

Replacement value of buildings is established at $\$ 2.2$ billion (original cost $\$ 519$ million). Replacement value of capital equipment is estimated at $\$ 1.4$ billion (original cost $\$ 814$ million) (CAMP/FY ‘96).

Approximately 300,000 s.f. of structures are defined as "not suitable for re-use." Approximately 650,000 s.f. of space is defined as "trailers" or "transportables."

\section{Los Alamos County (LAC)}

\section{Background}

No significant or applicable comments.

\section{Population}

New "senior housing" project is underway, an indication of the aging population.

\section{Housing}

No significant or applicable comments.

\section{Business and Non-Residential Facilities}

Significant new structures include the Library, the Bradbury Science Museum, a bank headquarters and two commercial office buildings adjacent to the Los Alamos Inn.

\section{Tourism}

No significant or applicable comments.

\section{Educational Facilities}

No significant or applicable comments. 
3.2 .7

3.2 .9

3.2 .10

\section{0}

4.1

4.2

4.3

\section{Transportation, Circulation and Accessibility}

The Los Alamos Airport will no longer be served by regular flights (Ross Air) after October 1, 1995. Discussions are on-going as to the status of the airport.

\section{Water Supply}

Discussions are on-going about a possible transfer of the water supply system to County ownership.

Income

No significant or applicable comments.

\section{County Revenues}

While County revenues from "non-federal" sources are increasing, self sufficiency has not been achieved and is the subject of on-going negations.

\section{Future Development}

\section{Planning Assumptions}

LANL is downsizing. While the extent and configuration of this trend is the subject of intense debate, it is clear that a leaner institution will result.

\section{Los Alamos National Laboratory}

Funding constraints and technological issues have significantly reduced or pushed out many projects having to do with the removal of decommissioned structures, the upgrading of infrastructure and maintenance of existing facilities.

Earlier indications that the use of trailers and temporary structures would be curtailed have not held true. The use of semi-permanent structures continues and presents significant fire protection problems.

\section{Los Alamos County}

The older, more fire-prone housing stock continues to be a major fire protection problem. Of equal concern, many of the newer "townhouse" units have been constructed with combustible materials and have minimal clearances one-to-another and between buildings and heavily wooded areas. These conditions present additional challenges to the Fire Department.

The demolition of older warehouse storage structures and replacement with a new bank headquarters is an encouraging sign. 


\subsection{Impact on Fire and Emergency Services}

The specific impact on fire and emergency services is discussed in the main body of the new assessment.

\section{Significant Developments Which Might Influence Needs}

We reaffirm the underlying principle that long range plans must be periodically reevaluated.

The LANL mission is being reshaped to contemporary needs. The major focus on environmental cleanup has and will present significant new challenges in fire protection. Further changes in mission, especially with respect to the weapons program and disarmament activities must be evaluated as these initiatives evolve.

The mix of contract personnel and "in-house" staff will continue to fluctuate. We foresee the decommissioning and decontamination program as an area wherein the use of contract personnel (low bidders!) will be extensive and the potential for lowered "fire prevention sensitivity" is significant.

Regulatory requirements which result in the accumulation of hazardous and/or flammable materials are now and will continue to be an important concern in terms of fire protection.

See prior comments regarding the airport.

Defibrillators are now part of LAFD equipment. 


\section{Needs Assessment}

\subsection{Existing Conditions Related To Fire Department Services}

$1.1 \quad$ Introduction

No significant or applicable comments.

1.2

\section{Los Alamos National Laboratory}

No significant or applicable comments.

\subsubsection{Nuclear Facilities}

While LANL/FSS-21 has released a statement to the effect that there is no "let-it-burn" policy, there may well be technical reasons why just such a course of action might be justified. We continue to find a division of opinions in this regard and recommend continued efforts to reach a consensus.

The LANL technical contribution to fire fighting plans can not be over emphasized. Without specific technical information, available only through LANL, pre-fire plans may be fatally flawed.

\subsubsection{LANL Non-Nuclear Facilities}

No significant or applicable comments.

\subsubsection{General Assessment/LANL}

Budget constraints and redirected policies have, in our opinion, significantly increased the fire risk at LANL. Areas of particular concern (discussed at length in the Reassessment and MasterPlan recommendations) include reduced reliability of in-place systems for fire detection, suppression and compartmentalization, further restrictions of access, differing approaches to fire protection from one facilities management area to another, continued (increased) use of temporary structures, and increased stockpiling of hazardous materials in fireprone areas.

Additionally, the political climate appears to have increased security concerns and the fire dangers associated therewith.

While LANL facilities continue to be designated as "Highly Protected Risks," the reported and observed degradation of various fire protection systems casts a measure of doubt on that assumption.

\section{General Assessment/LAC}

See prior comments regarding housing and older buildings. 
Building Managers do not always keep LAFD current. New management program also creates condition s wherein criteria and procedures vary from area to area, a situation which makes the planning and delivery of fire department services very difficult.

Hazardous Materials

Haz-Mat accumulation appears much greater.

LANL is considering turning Haz-Mat operations over to LAFD.

1.3.1

LANL

No significant or applicable comments.

1.3.2 Community

No significant or applicable comments.

1.3.3 General Assessment/Haz-Mat

No significant or applicable comments.

\subsection{Service Demand History}

\subsubsection{Fire Suppression/LANL}

Discussions indicate a reduction in reliability of built-in protections and reduction in fire protection efforts due to cut-backs in maintenance and increased requirements for compliance reporting. This is a major concern.

The risk potential for large scale incidents continues to be a major concern. LAFD does not have the manpower to deal with a major incident or one with technical complications.

\subsubsection{Fire Suppression/Community/Overall}

Latest workload figures continue to show low numbers.

\subsubsection{Airport Crash Fire/Rescue}

Ross Air will discontinue operations in October. Peacock Air is starting a limited service. LANL needs the airport. Status quo may remain for several months.

\subsubsection{Ambulance}

Long distance transportation continues to be an issue. DOE is considering privatization of EMS operations. 


\subsection{Service Demands Projections}

1.5.1 Fire Service Demand Projection/LANL

See prior comments regarding reduction in on-site fire protection.

1.5.2 Fire Service Demand Projections/Community

"Group-fire" and the dangerous conditions to be found in many older multiple dwellings remain as significant concerns.

See above comments.

Airport Crash Fire/Rescue Demand Projection

See prior comments.

1.5.4

Haz-Mat Demand Projection

See prior comments. Increased Haz-Mat cleanup is a major focus. Clean-up contractors are not as attuned to fire safety as they might be.

1.5.5 Ambulance Demand Projection

1.5.6 Wildland Fire Demand Projection

Wildland fire concerns remain very high.

1.6 Insurance Services Office (ISO) Rating

Water service upgrade projects are reported to be on hold or proceeding slowly. This continues to be a concern, especially at the developing waste management areas.

1.7 Community \& Wildland Interface

2.0 Existing Conditions - Fire Department

This information (Section 2.0) was provided by LAFD.

\section{$2.1 \quad$ Organization \& Management}

All chief officer/company officer positions filled by validated assessment center testing/independent firm.

Senior management team established.

Accountability/responsibility teams established.

Management plans/forecasting/assessing.

Development of self-assessment program for all divisions. 
IAFC fire department accreditation beta site.

Restricted organizational functions via self-audit.

Establishment of measurements and bench marks.

Administrative total quality program implementation.

Contractual compliance achieved.

Vision, mission, values published.

Six engine companies.

One ladder company.

Thirty-one (31) minimum staff.

One-hundred-three (103) line employees (DOE hiring freeze).

Emergency attack team/wildland (type II).

- eight staff members/interface USFS.

- wildland/interface manager.

\section{Management Information Systems.}

ADPE (automated data proc. equipment).

- networking denied/budget concerns.

- equipment denied/budget concerns.

- automation non-existent.

- 1970 technology.

- technical records management system non-existent.

Staffing Patterns

Engine 1: CO, D/E, FF.

Ladder 1: CO, D/E, 2 FF.

R-1: 2 FF.

Med: 1FF, 1FF/EMT-1.

CFR: CO, D/E. 
All line firefighters EMT's/ARFF/Wildland/Haz-Mat/Rad Worker.

Minimum staffing of thirty-one (31).

- Increased because truck company in service.

- DOE lowering minimum staffing ASAP.

Many units taken out of service on daily basis.

Three additional training officers.

All chief officers assigned automatic response status.

Response status changes.

- response district changes/reduce response times.

- commercial/residential high hazard considerations.

- identified in FCD 900.03.

- initial response 11-14 firefighters plus chief officers.

Call back procedures.

- draft FCD 900.05.

- community alert network system tested quarterly.

- thirty (30) additional pagers in service priority basis.

\section{General}

Assistant chief training/EMS relocated with administrative staff.

Three additional training officers.

- EMS.

- structural and AFFF.

- Haz-mat and tech. rescue (confined space).

Annual training calendar developed.

Training manuals being developed.

DOE halted auto. training record system. 
Training plan approved by DOE.

\section{4 .2}

\section{Hazardous Materials Training}

All uniformed personnel haz-mat operational level II.

All uniformed personnel meet DOE Rad Worker Requirement.

\subsubsection{Training Facilities}

Live burn facility out of service since 1994.

\section{$2.5 \quad$ Suppression Strategy and Tactics}

Ladder truck in service.

Fire ground accountability program initiated.

First due companies establish own water supply.

Use of ICS/IMS staging level I and level II.

Staffing levels below nationally recognized capabilities for multiple alarm fires.

\subsection{Fire Stations and Other Facilities}

Do not meet current mechanical, electrical, or fire codes - safety issue.

No vehicle exhaust systems - safety issue.

No automatic door openers/closures - safety issue.

Violation of DOE Order - sprinkler system requirements.

HVAC Systems need upgrade - UPS all stations.

\subsubsection{Stations}

\section{Station 1}

No significant or applicable comments.

\section{Station 2}

Confined space prop.

Ventilation prop.

Combat task test/physical fitness course.

Classrooms and offices recently remodeled. 
Drill tower/yard improvements.

\section{Station 3}

No significant or applicable comments.

\section{Station 4}

No significant or applicable comments.

\section{Station 5}

DOE recommends closure.

Impact of closure needs to be assessed.

\section{Station 6}

No significant or applicable comments.

\section{6 .2 \\ Other Facilities/LACFD and Related Agencies}

Headquarters relocated to Los Alamos.

TA-16 facility closed/environmental concerns.

LANL EOC TA-59 Building 1.

\section{7}

\section{Apparatus \& Equipment}

\subsection{1}

\section{Allocation}

Engine 50 and tanker 50 taken out of service by DOE.

Four tankers 9,000 gallon capacity.

Three mini-tankers with class A foam.

New rescue three with class $A$ foam.

Ladder one in service.

Technical rescue truck.

New rescue-1 with cascade system.

MCI trailer (EMS). 


\subsubsection{Condition of Apparatus}

2.7.3 Maintenance (Apparatus and Equipment)

\subsubsection{Adequacy}

Non-compliance NFPA and OSHA stds.

Ladder truck in service.

DOD and NFPA staffing recommendations not recognized by DOE.

SCBAs being upgraded to NFPA 1992 standard - pending DOE approval.

Wildland hand tools and equipment all upgraded.

Rescue tools upgraded.

Confined space rescue equipment purchased.

All uniforms/PPE meet or exceed NFPA standards.

2.8

\section{Hazardous Materials Response and Resources}

2.8.1

Incident Management/Community

Chief officers meet level V requirements.

One company officer CSTI level V instructor certified.

2.8.2 Incident Management/LANL

ICS deficiencies addressed.

FCD 400.15

\subsubsection{Nature of Material Involved}

LANL management deficient with response guidelines.

Policies for response to explosives and response to RAD in draft form from LANL.

Pre-fire plans in place for 50 nuclear facilities.

250 other LANL major facilities.

Radioactive Materials

No significant or applicable comments. 


\section{Nuclear Materials}

No significant or applicable comments.

\section{Explosives}

No significant or applicable comments.

\section{Other Hazardous Materials}

No significant or applicable comments.

\section{General Assessment}

No significant or applicable comments.

\section{Equipment and Haz-Mat Support}

3 CSTI certified haz-mat instructors.

PIC-6 GX-82s on all firefighting response apparatus.

SCBA upgrade 1992, pending DOE approval.

Upgrade 3 haz-mat equipment.

\section{Emergency Communications}

\subsubsection{Telephone}

Problems exist with 911 transfers (Community to LANL).

LANL, PSAP and CAS not capable of adequate emergency gathering or dissemination.

Hazards information inadequate.

LAFD "self-dispatching" impedes resource allocation.

LAFD resources are not "tracked" for status of location.

Mapping, pre-fire plans, hazards information, and resource availability is not automated or easily accessible during emergency response.

Benchmark times (enroute, on scene, etc...) are not accurate.

LANL PSAP operators are not trained for LAFD operations.

LANL PSAP operators are not trained to handle mutual aid communications.

LAFD has no authority or oversight of LANL PSAP operations. 
DOE has stopped efforts for dispatch capability for the LAFD.

2.9 .2

\section{Automatic Alarms}

\subsubsection{Radio}

Trunked radio system with dedicated channels for "dispatch," "tactical" operations, "medical" patient information, and channels for drills, hydrant testing, etc....

Chief officers equipped with "system level" portable radios capable of telephone interconnect and single point radio communications.

Chief officers equipped with multi-channel VHF portable radios for mutual aid communications.

Trunked radio installed at LAFD radio consoles for inter-agency communications.

Chief offers, medical units, and rescue vehicles equipped with cellular telephones.

Chief officers and personnel within the "immediate call-back area" equipped with Motorola tone and voice pagers on an upgraded LANL pager system.

Fire personnel entered in community alert network, telephone call-back system.

Medical units/rescue/EMS staff equipped with state-wide medical net.

CFR units with aircraft/airport radio capability.

Company inspection program.

Plan review, new construction, remodels, etc....

Community buildings inspected by fire marshal.

Commercial inspection program developed PIO program - training conducted.

Expanded public education program.

Fire investigation team established.

Company officer development includes fire investigation scene control.

Cross training with LAFD.

Expanded public education program to include firefighters.

2.11

\section{Alarm Response Assignments}

Changed response districts, FDC 900.03. 
$2.12 \quad$ Response Times

2.12.1 Community

Changed response districts, FDC 900.03.

2.12.2 LANL

Changed response districts, FDD 900.03.

Note DOE letter dated August 11, closure of Station 5 and other apparatus will constitute a service level degradation to LANL.

2.13

\section{Wildland Interface}

Refer to 2.5 .

Class A foam availability.

Increased wildland/interface training.

- all members USFS Red Card

- nine members on EAT team with special assignments

2.14

Mutual Aid

Overview

Mutual aid agreement with La Cueva.

Mutual aid agreement with LANL for specific functions.

Mutual aid agreements in attorney's office for completion.

Mutual aid not a viable source of supplemental resources for LANL.

The Memorandum of Agreement

No significant or applicable comments.

Prior to 1977

No significant or applicable comments.

March 1979

No significant or applicable comments. 
1988 to date

No significant or applicable comments.

2.15

\section{Airport Crash/Fire Rescue (CFR) Service DOE has determined both CFR units are not adequate.}

DOE has indicated airport support discontinued October 1, 1995.

Training for ARFF live burns /93, ‘94, '95 complete.

2.16

\section{Ambulance Services}

2.16.1

\section{Programmatic Capabilities}

Ambulance communications include radio and telephone capability for direct communications to local medical facilities (LAMC, LANL occupational health) and agencies operating the State of New Mexico Emergency Medical Radio Network.

LANL PSAP personnel provide basic location and nature of call information.

Ambulance response is "self dispatched".

\subsubsection{Equipment}

No significant or applicable comments.

\subsubsection{Facilities}

No significant or applicable comments.

2.16 .4

\section{Communications}

Information is often inadequate or incorrect due to lack of training or equipment problems.

LANL PSAP personnel are certified, but do not use medical protocol cards.

Ambulance response times recorded are inaccurate due to the lack of automated systems.

Ambulance resources are neither tracked for time or location.

2.16 .5

Personnel and Training

EMT-I/VT 20 personnel.

LANL receives EMT-1 on all medical calls.

EMT scope of practice upgrades implemented. 
2.16.6 Quality Assurance and Reporting.

Program compliant.

2.16.7 Mutual Aid Agreements

La Cueva.

LAMC.

LANL.

SM-409.

Special call assistance with private services.

Seven vehicles equipped with radio med-net capabilities.

2.16.8 Inter-Facility Transports

Capabilities for large scale transfers do not exist.

2.17

Wildfire Suppression

2.17.1

Program Organization And Management

No significant or applicable comments. See Section 2.13.

2.17.2 Wildland Fire Equipment

LAFD equipment is not suitable for wildland firefighting assignments.

2.17.3 Communications

See prior comments regrading LAFD.

2.17.4 Training For Wildland Fires

LAFD personnel have been trained in basic wildland fire technique and a nine (9) man team has been established.

2.17.5 Strategic Considerations

In-depth planning is limited. Wildland fires can be a significant threat to LANL. 
2.18

2.18.1

2.18 .2

2.18.3

$\mathbf{3 . 0}$

3.1

3.1 .1

3.1 .2

3.1 .4

3.2 .2

3.2 .3

\section{Pre-Emergency Planning}

Pre-incident Planning

\section{Emergency Response Drawings}

LAFD has developed drawings for most major facilities.

\section{Building Emergency Procedures}

Lack of detailed information on LANL facilities continue to be a major concern.

Los Alamos County Fire Department Pre-Fire Plan Program

Needs Assessment and Recommendations

\section{Levels of Fire Services Required}

DOE 420 and 470 may be replacing 5480.7.

\section{LANL}

See general comments in the LANL Needs Assessment.

\section{Community}

The level of service required in the community remains generally the same with specific concerns for newly developed areas.

\section{Airport}

See prior comments regarding the airport.

\section{Wildland Fires}

LAFD now has a nine (9) man Wildlands EAT team and does provide service (limited) in LAFSA. The problem remains.

\section{Level of Ambulance Services}

\section{Programmatic Requirements}

\section{Equipment}

Automatic defibrillation now provided on fire apparatus. Off-site transportation continues to be a problem, especially if a mass-casualty incident occurred.

\section{Facilities}

No significant or applicable comments. 


\subsubsection{Communications}

Centralized communications project was stopped. Linked systems and central dispatch remains a problem.

3.2.5 Personnel and Training

EMT-1 requirement is now met.

3.2.6 Quality Assurance and Reporting

No significant or applicable comments.

3.2.7 Mutual Aid Agreements

See other comments regarding Mutual Aid.

3.2.8 Inter-Facility Transports

Dr. Smith made a point regarding ambulance services needed to transport mass casualties. No such capacity exists.

\section{Applicable Standards}

\section{Department of Energy Orders}

DOE Order 5480.7 may be superceded.

\section{Federal and State of New Mexico Standards}

See comments in the main report.

\section{Organization and Management}

A policy and mission statement has been developed. A self-assessment program is in place.

\section{Training Program}

Cross-training is markedly improved. While training has greatly improved, drills do not seem to be the major focus (for LANL facilities). Training plan is in place.

In-house training is now the norm at LAFD.

Training manual is in-place. Flammable Liquids training has been completed. Haz-Mat training has been carried to the "operational level for most firefighters."

Familiarization tours at LANL have been conducted but the "operational" aspects of LANL firefighting appears to be far from understood. 


\subsubsection{Facilities}

On-site burn facility remains closed.

Station 6 reconfiguration has been completed.

Communication center project was stopped.

LAFD headquarters has been relocated near Station 6.

Pajarito Road Corridor continue to grow. Station 5 remains operational but evaluation continues.

\subsubsection{Staffing Patterns}

Truck 1 is in service and ladder training is part of regular program.

Two new rescue vehicles are in service and staffed. NFPA 1500 is recognized as the norm for SCBA interior work.

\section{4 .5}

\section{Emergency Communications}

\section{Portable Radio Fidelity}

See Section 2.0 for further comment.

\section{Use of Trunking System}

See Section 2.0 for further comment.

Fire Station Power

See Section 2.0 for further comment.

\section{All Calls to LACFD}

See Section 2.0 for further comment.

\section{Radio Repeater}

See Section 2.0 for further comment.

\section{Pagers}

See Section 2.0 for further comment.

\section{Outside Agencies}

See Section 2.0 for further comment. 
Tactical Channel

See Section 2.0 for further comment.

\subsection{Fire Department - Suppression Services} Recommendations

3.5 .1

\section{Strategy and Tactics}

Staffing flexibility is improved.

Mutual aid resources have proven to be of little value. Other avenues should be investigated.

\subsubsection{Apparatus and Equipment}

\section{Allocation/Replacement}

One tanker and one engine have been removed from operational status due to the cost of repairs $(\$ 5,000 ! ! !)$.

Two light rescue trucks are now in service.

\section{Maintenance}

No significant or applicable comments.

\section{Maintenance Records}

No significant or applicable comments.

\section{CFR Service}

CFR 60 is in service but DOE considers it non-compliant.

\section{CFR 6 Repair}

No significant or applicable comments.

\section{Adequacy of Fire Fighting Tools and Equipment}

Truck 1 is now part of the regular first response at LANL.

3.6

\section{Alarm Response}

See LANL evaluation and comments on staffing. 


\subsection{Response Times}

3.7.1 LANL

Response times at certain LANL facilities may have been significantly extended because of increased use of security fencing and electronic alarms.

3.7.2

\section{Community}

No significant or applicable comments.

3.8

\section{Fire Prevention}

\subsection{1}

\section{Community}

A fire marshal is now part of the staffing but has little or no impact on LANL except for leased facilities in town.

Other items not related to LANL.

Juvenile Program

No significant or applicable comments.

Inspections

No significant or applicable comments.

\section{Building Plans Evaluation}

No significant or applicable comments.

\section{Fire Safety Education}

No significant or applicable comments.

\section{Fire Investigation}

No significant or applicable comments.

\section{Residential Smoke Detectors}

No significant or applicable comments.

\section{Fire Safety Training for Children}

No significant or applicable comments.

\section{Roof Coverings}

No significant or applicable comments. 
3.8 .2

3.9 .1

3.9 .2

3.9 .3

3.10 .1

\section{LANL}

Fire prevention activities and in-place systems at LANL appear to have diminished and may further be reduced as part of budget cutting. This is a major concern.

\section{Hazardous Materials Recommendations}

\section{Incident Command}

No significant or applicable comments.

\section{Command Conflicts}

Command conflicts appear to have lessened but the whole issue of Haz-Mat operations is in flux.

\section{Training}

\section{Haz-Mat Training}

Site-specific LANL Haz-Mat training does not appear to have been developed as far as might be expected.

LANL is considering turning Haz-Mat operations over to LAFD.

\section{Radioactive Materials}

No significant or applicable comments.

\section{Inspections}

\section{LANL Familiarization}

LANL familiarization tours have been conducted but do not appear to have provided enough detailed information to firefighters.

Community Inspections

No significant or applicable comments.

\section{Pre-Fire Planning Recommendations}

Scope

No significant or applicable comments.

The Emergency Response Drawings

See comments in main report. 


\subsubsection{Emergency Response Guides.}

LAFD does not yet have a full understanding of the various hazards at LANL and thus does not have a clear picture of the "emergency responses" needed at all sites.

3.10.4 Pre-Fire Plan

Pre-fire plans are proceeding well but "training," as opposed to "familiarization" does not appear to be as well advanced as might be expected.

3.10.5 Familiarization and Training

3.11

\section{Wildland Fire Recommendations}

Wildland capabilities continue to be a serious concern.

3.12

Ambulance Services Recommendations

3.12.1 Programmatic Capabilities

Response capabilities for mass casualty incidents is limited.

\subsubsection{Equipment}

No significant or applicable comments.

\subsubsection{Communications}

See prior comments regarding communication.

\subsubsection{Personnel and Training}

EMT-I training and certification has expanded to the point where coverage is good.

\subsubsection{Quality Assurance and Reporting}

3.12.6 Mutual Aid Agreements

Mutual aid agreements have proven difficult to set in place and appear to of little real value except for requiring extended or reserve personnel. Consider other alternatives to meet immediate needs in the event of a major incident.

3.12.7 Inter-Facility Transports

See prior comments.

3.12.8 Additional Ambulance Service Recommendations

Mass casualty transportation capabilities are limited. 


\section{Training}

Training should be expanded to include full scope drills and LANL disaster scenarios.

\section{Medical Control}

No significant or applicable comments.

3.13

\section{Mutual Aid Recommendation/Fire Services}

Mutual Aid is a concept with limited value at LANL.

\section{DOE/LANL Recommendations}

Some improvement is noted in DOE/LANL/LAFD relationships but a lot of distance still must be covered.

See "Recommendations" for further discussions. 